University of Wollongong

Research Online

Faculty of Engineering and Information

Faculty of Engineering and Information

Sciences - Papers: Part B

Sciences

2019

Geogrid-confined pervious geopolymer concrete piles with FRPPVCconfined concrete core: Concept and behaviour

Haiqiu Zhang

University of Wollongong, hz593@uowmail.edu.au

Muhammad N. S Hadi

University of Wollongong, mhadi@uow.edu.au

Follow this and additional works at: https://ro.uow.edu.au/eispapers1

Part of the Engineering Commons, and the Science and Technology Studies Commons

Research Online is the open access institutional repository for the University of Wollongong. For further information contact the UOW Library: research-pubs@uow.edu.au 


\title{
Geogrid-confined pervious geopolymer concrete piles with FRP-PVCconfined concrete core: Concept and behaviour
}

\author{
Abstract \\ The use of fibre reinforced polymer (FRP) and polyvinyl chloride (PVC) as strengthening materials for \\ piles was found to be a promising scheme, due to their high strength-to-weight ratio, high durability and \\ high anti-corrosion ability. This study presents an experimental investigation of a new form of composite \\ piles: geogrid-confined pervious geopolymer concrete piles (GPGCPs) with fibre reinforced polymer (FRP)- \\ polyvinyl chloride (PVC)-confined concrete core (FPCC). The GPGCP with FPCC consists of a circular \\ geogrid outer tube, a FRP-PVC-confined normal geopolymer concrete core, and pervious geopolymer \\ concrete (PGC) filled in between. The reason for applying PGC into piles is to increase the rate of \\ consolidation. The aim of using FPCC is to improve the compressive strength and ductility of the \\ concrete. In this study, two groups of GPGCPs (without and with FPCC) were prepared and tested under \\ axial compression. In each group, one layer, two layers, and three layers of geogrid were used to \\ investigate the influence of the outer tube. The test results show that the FPCC can significantly improve \\ the mechanical behaviour of the GPGCPs. In comparison with GPGCPs without FPCC, the maximum axial \\ loads of GPGCPs with FPCC were higher, and the ductility was improved significantly.
}

\section{Keywords}

geopolymer, concrete, geogrid-confined, piles, concept, frp-pvcconfined, core:, pervious, behaviour

Disciplines

Engineering | Science and Technology Studies

\section{Publication Details}

Zhang, H. \& Hadi, M. N. S. (2019). Geogrid-confined pervious geopolymer concrete piles with FRP-

PVCconfined concrete core: Concept and behaviour. Construction and Building Materials, 211 12-25. 


\section{Geogrid-confined pervious geopolymer concrete piles with FRP-PVC-}

\section{3 confined concrete core: concept and behaviour}

4 Haiqiu Zhang ${ }^{1}$, Muhammad N.S. Hadi $^{2}$ *

$5 \quad{ }^{1}$ School of Civil, Mining and Environmental Engineering, University of Wollongong, Australia;

6 E-mail: hz593@uowmail.edu.au

$7 \quad{ }^{2}$ School of Civil, Mining and Environmental Engineering, University of Wollongong, Australia;

8 *Corresponding author, E-mail: mhadi@uow.edu.au

9 Abstract:

10 The use of fibre reinforced polymer (FRP) and polyvinyl chloride (PVC) as strengthening materials

11 for piles was found to be a promising scheme, due to their high strength-to-weight ratio, high

12 durability and high anti-corrosion ability. This study presents an experimental investigation of a

13 new form of composite piles: geogrid-confined pervious geopolymer concrete piles (GPGCPs) with

14 fibre reinforced polymer (FRP)-polyvinyl chloride (PVC)-confined concrete core (FPCC). The

15 GPGCP with FPCC consists of a circular geogrid outer tube, a FRP-PVC-confined normal

16 geopolymer concrete core, and pervious geopolymer concrete (PGC) filled in between. The reason

17 for applying PGC into piles is to increase the rate of consolidation. The aim of using FPCC is to

18 improve the compressive strength and ductility of the concrete. In this study, two groups of

19 GPGCPs (without and with FPCC) were prepared and tested under axial compression. In each

20 group, one layer, two layers, and three layers of geogrid were used to investigate the influence of

21 the outer tube. The test results show that the FPCC can significantly improve the mechanical

22 behaviour of the GPGCPs. In comparison with GPGCPs without FPCC, the maximum axial loads

23 of GPGCPs with FPCC were higher, and the ductility was improved significantly.

24 Keywords: FRP; PVC; Geogrid; pervious geopolymer concrete 


\section{Introduction}

26 The use of FRP has been increasing significantly in civil engineering applications, due to its high

27 strength-to-weight ratio, high durability, high anti-corrosion ability, satisfactory fire endurances

28 and bond strength [1-12]. The FRP materials can be used as various forms of lateral confinement

29 to strengthen the concrete columns, including fibre reinforced polymer (FRP) tubes [1-4], FRP

30 rings[13], FRP stirrups [14] and FRP helixes [15], FRP grids [16, 17]. Also, the externally bonded

31 FRP systems have been proven to be an effective way to strengthen the concrete beams or girders

$32[18,19]$. In addition, for piles, which are constructed in a marine environment, confinement by FRP

33 is superior to steel materials due to the higher durability and anti-corrosion ability [20-23]. The

34 USA is reported to spend more than $\$ 1$ billion annually to maintain waterfront piling systems.

35 Therefore, FRP materials are regarded as suitable alternatives in marine environments [24].

36 However, because the ultimate strain and ductility of FPR are relatively low, some researchers have

37 tried to apply plastic pipes such as high-density polyethylene (HDPE) and polyvinyl chloride (PVC)

38 to solve these problems. Kurt [25] first conducted experimental tests and theoretical analysis on

39 commercially available PVC tubes containing a concrete core. The PVC tubes were found to

40 increase the strength of the concrete core to approximately 3.2 times the pipe burst pressure.

41 Toutanji and Saafi [26] proposed a new hybrid column system consisting of concrete-filled PVC

42 tubes reinforced with external continuous impregnated FRP hoops at various spacings. The results

43 showed that using PVC-FRP tubes is an effective confinement technique that can significantly

44 increase both the strength and failure strains of concrete. Fakharifar and Chen [27] investigated the

45 mechanical behaviour of FRP-confined, PVC-confined and FRP-PVC-confined concrete. The

46 results showed that the ultimate strength and ultimate strain of FRP-PVC-confined concrete

47 specimens are larger than those of concrete columns confined by FRP alone or PVC alone. 
48 Buildings, structures and highway facilities are sometimes constructed on saturated soft soil areas.

49 To meet the requirements of allowable settlements and avoid failures, ground-improvement

50 technologies are applied. The use of permeable granular piles is one of the common methods and

51 includes sand compaction piles, stone columns, and rammed aggregate piers. The permeable

52 granular piles can improve the load carrying capacity and reduce the settlement, which is similar

53 to concrete, steel and wooden piles. However, the permeable granular piles have some advantages

54 over concrete, steel and wooden piles. The permeable granular piles can increase the rate of

55 consolidation and reduce the liquefaction potential caused by seismic and traffic loading [28-33].

56 The fast consolidation rate can effectively improve the elastic modulus of soft soil between piles,

57 and reduce the differential deformation between the top surface of piles and soft soil. However,

58 the strength and stiffness of permeable granular piles are relatively low, and their suitability in soft

59 soils is limited.

60 To solve this problem, two improvement methods can be applied. One method is to apply pervious

61 concrete piles as alternatives to granular piles. Pervious concrete piles can provide higher stiffness

62 and strength than those of granular piles without reducing the permeability [34, 35]. The

63 compressive strength of pervious concrete piles has been proven to be more than 10 times the

64 compressive strength of granular piles with similar permeability [34]. The other method is to use

65 geogrid and geotextile to encase the granular materials. These artificial materials have been proven

66 to significantly improve the strength of permeable granular piles without affecting the drainage

67 capacity. Recently, geogrid was used to confine and strengthen concrete members. Concrete

68 columns confined with geogrids have been found to provide higher deformation capacity than

69 unconfined concrete specimens [17, 36]. Until now, no studies combined the advantages of

70 pervious concrete and artificial materials to improve the performance of piles.

71 Recently, geopolymer concrete has gained a significant attention because the geopolymer binder

72 can replace ordinary Portland cement (OPC) and substantially reduce the emission of $\mathrm{CO}_{2}$ [37]. 
73 Several studies have investigated the performance of pervious geopolymer concrete (PGC) [38,

74 39]. It has been proven that the properties of PGC are similar to those of conventional pervious

75 concrete.

76 In the present study, a new composite confinement system named geogrid-confined pervious

77 geopolymer concrete piles (GPGCPs) is proposed. The aim of this new pile form is to combine the

78 advantages of FRP, PVC, and PGC. The tests were divided into two groups: GPGCPs with and

79 without FPR-PVC-confined concrete core (FPCC). The FPCC was made by filling the normal

80 geopolymer concrete (NGC) into FPR-PVC tubes. One layer, two layers and three layers of geogrid

81 tubes were used to investigate the effect of the amount of geogrid on the axial compressive

82 behaviour of the concrete specimens. Here, the rationale for the new pile form and the testing results

83 are presented to characterise the expected advantages.

\section{2. Experimental Programme}

\section{2.1. Preliminary Tests}

86 The preliminary tests examined the properties of four pairs of samples, including one pair of plain

87 PGCs, one pair of plain NGCs, one pair of FRP-PVC tubes, and one pair of FPCCs. The aim of

88 plain NGC and PGC tests is to obtain the axial stress-axial strain curves and the ductility of the

89 reference samples. The diameter of NGC samples and PGC samples was $150 \mathrm{~mm}$ and their height

90 was $300 \mathrm{~mm}$. The aim of FRP-PVC tube and FPCC tests is to obtain their contribution to the vertical

91 load carrying capacity of GPGCPs. The inner diameter and outer diameter of PVC tubes were 76

$92 \mathrm{~mm}$ and $84 \mathrm{~mm}$, respectively. The height of PVC tubes was $325 \mathrm{~mm}$. The inner diameter and outer

93 diameter of FRP-PVC tubes were $76 \mathrm{~mm}$ and $86 \mathrm{~mm}$, respectively. The height of FRP-PVC tubes

94 was $325 \mathrm{~mm}$. The FPCC samples were made by filling NGC into FRP-PVC tubes. One strain gauge

95 was used for each FPCC sample to obtain the hoop strain during the axial compression test. This 
96 strain gauge was attached transversely onto the mid-height of the outside surface. The details of

$97 \quad$ FPCC are shown in Fig. 1.

98 The four pairs of samples are named as follows: (a) P denotes plain PGC; (b) N denotes plain NGC;

99 (c) FP denotes FRP-PVC tubes; (d) FPCC denotes the FRP-PVC-confined NGC; (e) the last 100 numbers 1 or 2 are used to distinguish between the two nominally identical specimens. The details

101 of preliminary tests are summarised in Table 1.

102 2.2. Test Matrix

103 A total of 12 GPGCP specimens were cast and tested under axial compression. All specimens were

$104160 \mathrm{~mm}$ in diameter and $325 \mathrm{~mm}$ in height. These specimens were divided into two groups. The

105 six specimens of the first group did not have FPCC (shown in Fig. 2(a)). The six specimens of the

106 second group had FPCC (shown in Fig. 2(b)). To ensure more representative results, two nominally

107 identical specimens for each specimen configuration were tested.

108 The labelling of each specimen is named as follows: (a) GG denotes GPGCPs without FPCC, and

109 the number afterwards denotes the number of geogrid layers (one, two and three layers); (b) GGC

110 denotes GPGCPs with FPCC, and the number that follows denotes the number of geogrid layers

111 (one, two and three layers); (c) the last number 1 or 2 is used to distinguish between the two

112 nominally identical specimens. For example, Specimen GG2-2 represents the second of the two

113 identical GPGCPs without FPCC that were confined with two layers of geogrid. The details of the

114 GPGCPs specimens are summarized in Table 2. The detailed section configurations are shown in

115 Fig. 3.

116 2.3. Preparation of Specimens

117 2.3.1. Geopolymer Concrete 
118 The mix proportions for PGC and normal geopolymer concrete (NGC) are shown in Table 3. All

119 mixes were conducted under ambient conditions $\left(23 \pm 2{ }^{\circ} \mathrm{C}\right)$. In this study, ground granulated blast

120 furnace slag (GGBFS) and Class F fly ash (FA) were used as an aluminosilicate source. The

121 GGBFS was supplied by the Australasian Slag Association, Australia [40], and the Class F FA was

122 provided by the Eraring Power Station, Australia [41]. The FA was classified as Class F according

123 to AS 3582.1 [42]. The alkaline activator was made by blending sodium hydroxide solution with

124 sodium silicate solution. The concentration of sodium hydroxide solution was kept constant (14 M)

125 for all mixtures. Sodium silicate solution was purchased from a local commercial supplier. The

126 mass ratio of $\mathrm{SiO}_{2}$ to $\mathrm{Na}_{2} \mathrm{O}$ of the sodium silicate was 2.02 with a chemical composition of $29.6 \%$

$127 \mathrm{SiO}_{2}$ and $14.7 \% \mathrm{Na}_{2} \mathrm{O}$. The sodium hydroxide solution and sodium silicate solution were mixed

128 together for 1 hour before being mixed with the aluminosilicate materials. The size of the coarse

129 aggregates ranged from $5 \mathrm{~mm}$ to $12 \mathrm{~mm}$.

130 The mixing procedures for the normal and PGC samples were the same. The geopolymer concrete

131 was prepared by mixing the dry materials with the alkaline activator in a Lightburn 65 litre mixer.

132 The dry materials were dry mixed for $2 \mathrm{~min}$, then the alkaline activator was added to the mix and

133 mixed for $1 \mathrm{~min}$. Then, the additional water was poured into the mixer and mixed for another 2

134 min. After mixing, the fresh concrete was cast layer by layer into the moulds, and the depth of every

135 layer was approximately $50 \mathrm{~mm}$. Each layer was vibrated for $10 \mathrm{~s}$ on a vibration table. The

136 specimens were left in the laboratory at an ambient condition for 24 hours, then covered by hessian

137 clothes to prevent losing moisture from the concrete.

138 2.3.2. Geogrid tubes

139 For GPGCPs, to provide lateral confinement to the concrete specimens, the geogrid was formed 140 into tubular shapes, and the ends were held with plastic ties. To ensure that the geogrid would not 141 be loosened or slid under axial load, the geogrid was overlapped at an approximate length of 80 
$142 \mathrm{~mm}$. To maintain the same dimensions of all concrete cores, the inner diameter of the geogrid tubes

143 was kept at $160 \mathrm{~mm}$ (not including the thickness of the geogrid tube). The height of geogrid tubes

144 was $325 \mathrm{~mm}$.

\section{$145 \quad$ 2.3.3. FRP-PVC tubes}

146 The PVC tubes were wrapped by GFRP to form FRP-PVC tubes using the wet layup method. The

147 inner diameter and outer diameter of PVC tubes were $76 \mathrm{~mm}$ and $84 \mathrm{~mm}$, respectively. The height

148 of PVC tubes was $325 \mathrm{~mm}$. At first, the GFRP sheets were impregnated with a mixture of epoxy

149 resin and hardener at a ratio of 3:1. After that, the impregnated GFRP sheets were wrapped on the

150 PVC tubes in five layers with an overlapping length of $150 \mathrm{~mm}$. The FRP-PVC tubes were then

151 cured in the laboratory for 1 day. These FRP-PVC tubes were used as the mould for casting the

152 NGC. The outer diameter and height of FRP-PVC tubes were $86 \mathrm{~mm}$ and $325 \mathrm{~mm}$, respectively.

153 The inner diameter was same as that of PVC tubes $(76 \mathrm{~mm})$. The detailed section configuration of

154 FPCC is shown in Fig. 2(a).

\section{2.4. Material Properties}

\section{2.4.1. Geopolymer Concrete}

157 The compressive strength of the plain pervious and normal geopolymer concrete was determined

158 according to AS 1012.9 [43]. Three NGC cylinders and three PGC cylinders with 100 mm diameter

159 and $200 \mathrm{~mm}$ height were tested to determine the 28-day compressive strength. Because the two

160 groups of geogrid-confined pervious geopolymer concrete piles (GPGCPs) were produced in

161 different batches, the compressive strengths of the PGC in the two groups of tests were different.

162 However, the difference was minimal. The average 28-day compressive strength of PGC for

163 GPGCPs without FPCC was 22.1 MPa; that of GPGCPs with FPCC was 21.7 MPa. The average

164 28-day compressive strength of NGC for GPGCPs with FPCC was 49.2 MPa. The permeability of 
165 PGC were obtained by using the method proposed by Aoki et al. [44], and its average value was $1669.1 \mathrm{~mm} / \mathrm{s}$.

\section{2.4.2. Geogrid}

168 The uniaxial geogrid (shown in Fig. 4(a)) were used as the outer confinement material. The inner

169 dimensions of its square openings are $25 \mathrm{~mm} \times 25 \mathrm{~mm}$, which was measured by a standard ruler

170 with an accuracy of $0.5 \mathrm{~mm}$. The geogrid was manufactured from glass fibre with a bitumen

171 coating. The uniaxial geogrid can resist corrosion and has a large tensile rupture strain. The widths

172 of the transverse ribs and the longitudinal ribs were measured by a digital Vernier calliper, which

173 are $10 \mathrm{~mm}$ and $6 \mathrm{~mm}$, respectively. The thicknesses of the transverse rib and the longitudinal ribs

174 were measured by a digital Vernier calliper, which are $1.5 \mathrm{~mm}$ and $1.0 \mathrm{~mm}$, respectively. The

175 mechanical properties of the uniaxial geogrid were determined by applying the ASTM D6637-M15

176 standard [45]. The length of each test transverse rib between the testing machine clamps was 150

$177 \mathrm{~mm}$, which was measured by a standard ruler with an accuracy of $0.5 \mathrm{~mm}$. Five single transverse

178 geogrid ribs were prepared and tested by using $100 \mathrm{kN}$ Instron testing machine at the High Bay

179 Laboratory, University of Wollongong, Australia. The tensile testing rate was $5 \mathrm{~mm} / \mathrm{min}$. The

180 tensile load-axial strain curves of the geogrid are depicted in Fig. 4(b). The average tensile ultimate

181 load of geogrid ribs was $2.8 \mathrm{kN}$ and the average ultimate tensile strain was $9.2 \%$.

182 2.4.3. Fibre reinforced polymer

183 In this study, glass fibre reinforced polymer (GFRP) was chosen as the reinforcement material. The

184 GFRP sheets were formed from bidirectional glass fibre and had a nominal thickness of $0.15 \mathrm{~mm}$.

185 The GFRP sheets were first impregnated with a mixture of epoxy resin and hardener at a ratio of

186 3:1. Then, these sheets were cured in the laboratory for 1 day. Flat coupon tests were conducted

187 according to ASTM D7565 [46]. The width of the test coupon was $25 \mathrm{~mm}$ and the length measured

188 between the testing machine clamps was $200 \mathrm{~mm}$. The longitudinal strain was measured by using 
1893 strain gauges on the two sides of the test coupon (shown in Fig. 5). The aforementioned $100 \mathrm{kN}$

190 Instron testing machine was used to test the coupons at a loading rate of $2 \mathrm{~mm} / \mathrm{min}$. Five coupons

191 were tested. The test results showed that the average tensile strength, elastic modulus and ultimate

192 tensile strain were 621.5 MPa, 33.4 GPa and 1.86\%, respectively, as shown in Table 4.

\section{2.4.4. PVC}

194 The commercial PVC pipes were used in this study, with an outside diameter of $84 \mathrm{~mm}$ and a

195 thickness of $4 \mathrm{~mm}$. The tensile tests of PVC coupons were conducted based on ASTM D638 [47].

196 Five dog-bone coupons (Fig. 6(a)) were cut from the PVC tube. The width of the narrow section of

197 the dog-bone coupon was $13 \mathrm{~mm}$ and the length between the testing machine clamps was $115 \mathrm{~mm}$.

198 The tensile tests were carried out using the aforementioned $100 \mathrm{kN}$ Instron testing machine at a

199 loading rate of $5 \mathrm{~mm} / \mathrm{min}$. Figure 6(b) represents the tensile load-axial strain behaviour of the PVC

200 coupon tests. The average tensile strength, fracture stress, elastic modulus and ultimate tensile

201 strain were 51.2 MPa, 42.7 MPa, 1.58 GPa and 55.4\%, respectively, as shown in Table 4. The PVC

202 coupon specimens were found to exhibit much higher ductility than the FRP coupons.

203 2.5. Instrumentation and testing procedure

204 All of the preliminary test samples and GPGCP specimens were tested by using the Denison 5000

$205 \mathrm{kN}$ testing machine in the High Bay Laboratory at the University of Wollongong, Australia. The

206 GPGCP specimens were capped with high-strength plaster at the top and bottom ends to ensure

207 that the axial compression load was evenly applied onto the specimens. The axial deformation were

208 measured using two Linear Variable Differential Transformers (LVDTs), which were fixed at the

209 opposite corners between the loading and supporting steel plates. All the specimens were axially

210 loaded up to $50 \mathrm{~mm}$ displacement at a rate of $1 \mathrm{~mm} / \mathrm{min}$. 
211 For each FRP-PVC confined concrete (FPCC) specimen, a strain gauge was attached transversely

212 onto the mid-height of the outside surface (shown in Fig. 1). The purpose of this gauge was to

213 obtain the hoop strain during the tests.

214 For each GPGCP without FPCC specimen, three strain gauges were used to monitor the hoop strain.

215 All these strain gauges were attached transversely onto the outside surface of transverse ribs of

216 geogrid tubes. One strain gauge was attached at the mid-height transverse rib of the geogrid tubes,

217 and two other strain gauges were attached at the second top and second bottom transverse ribs of

218 the geogrid tubes, respectively. Figure 3(a) clearly shows the locations of these strain gauges.

219 For each GPGCP with FPCC specimen, four strain gauges were used to monitor the hoop strain.

220 Three of them were attached transversely onto the outside surface of transverse ribs of geogrid

221 tubes (shown in Fig. 3(b)). Their positions are same as those of GPGCPs without FPCC specimens

222 described above. Another strain gauge was attached at the mid-height of the outside surface of the

223 FRP-PVC-confined concrete, shown in Fig. 1.

224 In general, the ultimate axial strains of confined concrete columns are no more than $5 \%[3,48,49]$

225 because after reaching this value of axial strain, the load carrying capacity of columns decreases

226 significantly, and the small remaining load carrying capacity is not considered. Another reason is

227 that such large deformation are not allowed for structural members in practice. However, for

228 granular piles encased by geosynthetics in the laboratory or on site, the axial strain can reach as

229 high as $15 \%$ [50]. Therefore, in this study, to investigate if the GPGCPs can allow for such high

230 deformation, the ultimate axial deformation was set to $50 \mathrm{~mm}$, corresponding to an axial strain of

$231 \quad 15.4 \%$.

\section{3. Test results and analysis}

233 3.1. Preliminary tests 
234 The preliminary test results are summarised in Table 5. The axial load-axial strain relationships of 235 two plain PGC specimens and two plain NGC specimens are shown in Fig. 7. All plain PGC 236 specimens and NGC specimens failed due to the crushing and spalling of concrete at the mid-height 237 of the specimens.

238 To estimate the contribution of FRP-PVC tubes to the axial load carrying capacity, two specimens 239 were axially loaded. Figure 8(a) shows that the two FRP-PVC tubes failed due to local elephant-

240 foot buckling and rupture of the GFRP. The axial stress-axial strain relationships are illustrated in

241 Fig. 8(b). The compression tests were stopped when the axial deformation reached $50 \mathrm{~mm}$ (the 242 axial strain was 15.4\%). The axial behaviour of the FRP-PVC tubes consisted of three branches. In

243 the first branch, the axial stress increased rapidly to the peak stress. In the second branch, the FRP

244 jacket ruptured, and the axial stress decreased sharply to a low level. After that, in the third branch,

245 the axial stress was kept stable at a very low level.

246 Two FRP-PVC-confined concrete specimens were tested to determine their compressive

247 behaviour, and their dimensions and section configurations are shown in Fig. 1. The final state of 248 the FRP-PVC-confined concrete is shown in Fig. 9. The FRP jacket separated from the specimens, 249 and the PVC tubes expanded and were distorted significantly. The axial stress-axial strain 250 behaviour, shown in Fig. 10, is similar to that observed in a previous study conducted by Fakharifar 251 and Chen [27]. The axial stress-axial strain curve consists of a parabolic first branch, a linear second 252 branch and a descending third branch. The peak stress was reached at the end of the second branch 253 when the GFRP ruptured. Then, the axial stress decreased rapidly and gradually stabilized. The 254 compression tests were continued until the specimens reached an axial deformation of $50 \mathrm{~mm}$ (axial 255 strain of 0.154$)$. Figure 11 represents the axial strain versus hoop strain curves of two FPCCs from 256 the beginning of the tests to the rupture of the GFPR jackets.

\section{3.2. Final state of GPGCPs}


258 The typical final state of the representative specimens after the tests is illustrated in Fig. 12 and Fig.

259 13. In this study, only two specimens failed due to the failure of the geogrid: GG1-1 and GG1-2,

260 which were wrapped by one layer of geogrid without FPCC. One of the failed specimens is shown

261 in Fig. 12(a). All other specimens reached an axial strain of 15.4\% (corresponding to an axial

262 deformation of $50 \mathrm{~mm}$ ) without obvious failure. During the tests, for all GPGCPs, only a small

263 number of course aggregates were squeezed out through the opening of the geogrid. Although the

264 expansion of specimens was large, the geogrid tube held most of the coarse aggregates in the

265 pervious geopolymer concrete.

266 Further examination of the final states of the GPGCPs without FPCC specimens indicated that the

267 upper half of GG2 specimens expanded more due to the non-uniform dilation of the PGC, as shown

268 in Fig. 12(b). However, the GG3 specimens expanded uniformly, and no prominent local bulging

269 was observed, as shown in Fig. 12(c). For the final states of the GPGCPs with FPCC, the GGC1

270 specimens expanded at the mid-height of the specimen, as shown in Fig. 13(a). The specimens of

271 GGC2 and GGC3 expanded uniformly over the entire height (shown in Fig 13(b)(c)), which were

272 similar to GG3 specimens.

273 3.3. Mechanical behaviour of GPGCPs without FPCC during the axial compression test

274 3.3.1. Axial stress-axial strain behaviour

275 The key testing results of GPGCPs without FPCC are summarized in Table 6. The detailed axial 276 stress-axial strain behaviour of the three pairs of GPGCPs without FPCC specimens is depicted in

277 Fig. 14. All specimens showed a similar mechanical performance. The axial stress-axial strain 278 behaviour of these specimens of GPGCPs without FPCC can be divided into three branches. In the 279 first branch, their axial stress increased rapidly to the peak stress. It was found that their peak stress 280 was not enhanced and was very close to the compressive strength of the unconfined PGC. The axial 281 strains at the peak stress were also close to the axial strains of the unconfined PGC. In other words, 
282 the geogrid tubes alone did not enhance the compressive strength of the PGC. This is because the

283 confinement effect provided by geogrid tubes was small due to the low elastic modulus and large

284 openings of the geogrid tubes.

285 In the second branch, after the peak stress, the axial stress decreased sharply. Even though the

286 lateral expansion of the concrete became larger at this stage, the confinement effect provided by

287 the geogrid was not significant because the tensile elastic modulus of the geogrid was relatively

288 low and the openings were large. During the test, although the coarse aggregates did not spall from

289 the openings of geogrid, these aggregates were somewhat ejected.

290 In the third branch, after the pronounced reduction in the axial stress, the GPGCPs without FPCC

291 lost approximately $70 \%$ to $80 \%$ of the load carrying capacity. However, after an axial strain of 0.04 ,

292 the axial stress stabilized without any significant change because with increasing the axial strain,

293 the hoop strain became more pronounced, and the confining pressure provided by the geogrid

294 became much higher. When the confining pressure achieved a certain level, the axial stress of the

295 confined concrete was held steady even though the axial strain was large. However, Specimens

296 GG1-1 and GG1-2, which had only one layer of geogrid, failed before reaching an axial strain of

$297 \quad 15.4 \%$

298 The different layers of the geogrid had a significant influence on the mechanical behaviour in the

299 third stage only. With additional layers of geogrid, the stable axial stress level increased. It is

300 estimated that the stable axial stress increased by approximately 1.2 MPa for each additional layer

301 of geogrid.

302 3.3.2. Axial-hoop strain behaviour

303 Figure 15 shows the axial-hoop strain curves of GPGCPs without FPCC. The axial strains were 304 obtained from the measurement of the linear variable differential transformer (LVDT), while the 
305 hoop strains were averaged from three strain gauges attached at the geogrid ribs. When the axial

306 strain was smaller than 0.01 , the differences of the three pairs of specimens were very close.

307 However, when the axial strain increased from 0.01 to the end, the difference between the

308 specimens became increasingly significant. With additional geogrid layers, the rate of increase of

309 the hoop strain decreased considerably. Here, more layers of geogrid resulted in more confining

310 pressure, leading to smaller hoop strain.

311 3.4. Mechanical behaviour of GPGCPs with FPCC during the axial compression test

312 3.4.1. Axial stress-axial strain behaviour

313 The key test results of this part are summarized in Table 7. The detailed axial stress-axial strain

314 behaviour of the three pairs of GPGCPs with FPCC specimens is depicted in Fig. 16. All specimens

315 in this part exhibited similar mechanical performance, and the most notable result was the presence

316 of two peak axial stresses.

317 The axial behaviour of these specimens consisted of four branches. In the first branch, the axial

318 stress of GPGCPs with FPCC increased rapidly to the first peak axial stress, which is similar to

319 GPGCPs without FPCC. The axial strains at the first peak axial stress were close to the axial strain

320 at the peak axial stress of unconfined PGC (around 0.002). During the tests, when the specimens

321 reached the first peak axial stress, the outer PGC cracked. In other words, at that moment, the outer

322 PGC reached its peak axial stress.

323 In the second branch, after the first peak stress, the axial stress decreased rapidly. At the end of this

324 branch, the axial stress of all specimens decreased by approximately $5 \mathrm{MPa}$, and the axial strain

325 reached approximately 0.007 .

326 In the third branch, the axial stress increased by approximately $5 \mathrm{MPa}$ and reached the second peak

327 axial stress. At the end of the third branch, the axial strain reached approximately 0.025 , at which 
328 point the GFPR jacket ruptured, as confirmed by audible cracking of the GFRP jackets. The reason

329 for the increase in the axial stress is that with increasing axial strain, the PFCC provided more load

330 carrying capacity. This observation can be confirmed by the test results of FPCC alone in Fig. 10,

331 showing that the axial stress increased until the axial strain reached approximately 0.025 . It can be

332 found from the Table 7 that the values of second peak axial stress were slightly smaller than the

333 first ones. Therefore, the first peak axial stress were the maximum axial stress.

334 In the last branch, after the second peak axial stress, the axial stress decreased until the end of the

335 compression tests. The rate of decrease reduced with increasing the axial strain. As the axial strain

336 exceeded 0.14 , the axial stress stabilized because when the hoop strain became more pronounced,

337 the confining pressure provided by the geogrid was sufficient to stop the decrease in axial stress.

338 The final average axial stress were approximately $25 \%$ to $40 \%$ of the nominal maximum average

339 axial stress. Only in the fourth branch, the different numbers of geogrid layers had a prominent

340 influence on the mechanical behaviour. With additional geogrid layers, the axial stress was higher.

341 This trend is similar to the trend of GPGCPs with FPCC.

\section{$342 \quad 3.4 .2$. Hoop strain distribution}

343 The axial-hoop strain curves of geogrid tubes in GPGCPs with FPCC are shown in Fig. 17. The

344 measurement methods are same as the measurement methods used for GPGCPs without FPCC.

345 The shape of the curves and the development trends are same as those of GPGCPs without FPCC.

346 The final average hoop strain of Specimens GGC2 and GGC3 decreased by $31.7 \%$ and 51.6\%,

347 respectively, relative to the final average hoop strain of Specimens GGC1. In other words, the use

348 of additional geogrid layers can significantly reduce the hoop strain.

349 In addition, the axial-hoop strain relationships of FPCC placed in the middle of GPGCPs were also 350 obtained using strain gauges attached at the mid-height of the FPCC (shown in Fig. 18). The test 351 results of hoop strain terminate at the point where GFRP jackets rupture. The testing results of 
352 FPCC alone are also included in Fig. 18. There were no prominent differences between these sets

353 of results. In other words, the outer PGC and geogrid tubes have almost no influence on the

354 mechanical behaviour of FPCC, possibly because the confinement effect provided by the outer

355 PGC and geogrid tube is marginal.

356 3.5. Comparison between two groups of GPGCPs

$357 \quad$ 3.5.1. Axial stress-axial strain relationships

358 Figure 19(a), Figure 20(a) and Figure 21(a) show the comparisons between the axial stress-axial

359 strain curves of GPGCPs with and without FPCC with the same number of geogrid layers. In each

360 figure, the first peak axial stress (maximum axial stress) of all GPGCPs with FPCC were

361 approximately $20 \%$ higher than the peak axial stress of all GPGCPs without FPCC. In addition, in

362 each figure, the final axial stress of GPGCPs with FPCC were approximately $45 \%$ higher than the

363 final axial stress of GPGCPs without FPCC. Thus, using FPCC has the advantage of increasing the

364 axial load carrying capacity.

365 3.5.2. Hoop-axial strain

366 The comparisons between the axial-hoop strain curves of GPGCPs with and without FPCC with

367 the same number of geogrid layers are shown in Fig. 19(b), Fig. 20(b) and Fig. 21(b). It is found

368 that in each figure, the hoop strains of GPGCPs without FPCC was slightly higher than those of

369 GPGCPs with FPCC. However, the use of FPCC has no significant effect on the hoop strain.

370 3.5.3. Ductility

371 The ductility of concrete members is regarded as one of the most important design aspects. The

372 ductility calculation method proposed by Park [51] was adopted in this study, as shown in Equation $373(1)$ : 


$$
\mu_{\varepsilon}=\frac{\varepsilon_{u}}{\varepsilon_{y}}
$$

374 where $\mu_{\varepsilon}$ is the specimen ductility. In general, $\varepsilon_{u}$ is defined as the specimen strain at $85 \%$ of the 375 maximum stress at the descending branch (for unconfined specimens) or is equal to the ultimate 376 strain (for FRP-confined concrete, it is the strain at the point of FRP rupture). The $\varepsilon_{y}$ is the yield 377 strain, which is the axial strain at the yield stress.

378 In this study, the definition of $\varepsilon_{u}$ proposed by Wang et al. [36] was adopted, which defines $\varepsilon_{u}$ as the 379 axial strain at $50 \%$ of the maximum stress at descending branch, which is shown in Fig. 22. This is 380 because this definition can more clearly demonstrate the differences in ductility for the concrete 381 confined by the geogrid.

382 The yield strain $\varepsilon_{y}$ was the strain at the yield stress. Here, the yield stress was obtained based on the 383 method proposed by Park [51]. The yield stress corresponds to the intersection point between a

384 horizontal line drawn from the first peak axial stress and the straight line passing through the origin 385 and the point representing $75 \%$ of the first peak axial stress. There were three different types of 386 stress-strain curves were observed in this study, and the positions of yield strain are shown in Fig. 38722.

388 The ductility results of this study are summarized in Table 8. Compared with those of plain PGCs, 389 the ductility results for Specimens GG1, GG2 and GG3 were improved by $1.7 \%, 11.3 \%$ and 20.9\%, 390 respectively. In other words, the geogrid alone cannot effectively enhance the ductility of pervious 391 concrete piles. However, when the FPCC was included, the ductility of the piles increased

392 significantly. The ductility results for Specimens GGC1, GGC2 and GGC3 were 22 times, 25 times 393 and 30 times the ductility results for plain PGC, respectively. In addition, with additional geogrid 394 layers, the ductility results of both groups of GPGCPs increased. 


\section{Conclusions}

396 This study presents and explains the results of axial compression tests on geogrid-confined

397 pervious geopolymer concrete piles (GPGCPs) with and without FRP-PVC-confined

398 concrete core (FPCC). The axial stress-axial strain behaviour, axial-hoop strain behaviour and

399 final state of the specimens have been discussed. According to the test results and discussions

400 presented above, the following conclusions can be drawn:

401 1. For GPGCPs without FPCC, in comparison with plain PGC, geogrid tubes alone cannot

402 effectively improve the maximum axial stress and axial strain at the maximum axial stress. This

403 is because the confinement effect provided by the geogrid is relatively low. Only after the

404 maximum axial stress, the effects of the geogrid tubes became clear. When the number of

405 geogrid layers increased, the axial stress increased slightly. However, the effects of geogrid on

406 hoop strain was significant. When the number of geogrid layers increased, the hoop strain

407 decreased significantly.

408 2. For the GPGCPs with FPCC, two peak axial stresses appeared, and the values of these two

409 peak axial stresses were close. The first peak axial stress, which was the maximum axial stress,

410 was approximately $20 \%$ higher than the maximum axial stress of GPGCPs without FPCC. The

411 effects of geogrid on axial stress of GPGCPs with FPCC were similar to those of GPGCPs

412 without FPCC. Only after the second peak stress the effects of geogrid tubes became clear.

413 When the number of geogrid layers increased, the axial stresss of GPGCPs with FPCC

414 increased.

415 3. The incorporation of FPCC into GPGCPs did not have a significant influence on the hoop strain 416 of the outer geogrid tubes. The effects of geogrid on hoop strain of GPGCPs with FPCC is 417 similar to those of GPGCPs without FPCC. When the number of geogrid layers increased, the 
418 hoop strain of GPGCPs with FPCC decreased significantly. When the number of geogrid layers

419 was same for GPGCPs with and without FPCC, their hoop strains were close.

420 4. All GPGCPs can bear a large axial strain due to the high ductility of the geogrid. In comparison 421 with the ductility of plain PGC, the ductility of GPGCPs without FPCC was not effectively 422 enhanced. However, when the FPCC was applied, the ductility of the GPGCPs with FPCC 423 improved significantly.

424 The focus of this paper is to present the new idea of GPGCPs with FPCC, and present the 425 results of experimental work. The future investigation of analytical and numerical models 426 about this new type pile is ongoing at the University of Wollongong, Australia.

\section{Acknowledgements}

428 The authors gratefully acknowledge the contributions of Mr. Ritchie Mclean for his help in carrying 429 out the experiments. The authors thank the Australasian Slag Association for providing GGBFS 430 and Eraring power station for providing fly ash. The first author acknowledges the China 431 Scholarship Council and the University of Wollongong, Australia for supporting his PhD 432 scholarship.

\section{References}

434 [1] Hadi, M.N.S., Behaviour of FRP wrapped normal strength concrete columns under eccentric 435 loading. Composite Structures, 2006. 72(4): p. 503-511.

436 [2] Hadi, M.N.S., Khan, Q.S., and Sheikh, M.N., Axial and flexural behavior of unreinforced and 437 FRP bar reinforced circular concrete filled FRP tube columns. Construction and Building Materials, 438 2016. 122: p. 43-53. 
439 [3] Csuka, B. and Kollár, L.P., FRP-confined circular concrete columns subjected to concentric 440 loading. Journal of Reinforced Plastics and Composites, 2010. 29(23): p. 3504-3520.

441 [4] Mai, A.D., Sheikh, M.N., and Hadi, M.N.S., Investigation on the behaviour of partial wrapping

442 in comparison with full wrapping of square RC columns under different loading conditions.

443 Construction and Building Materials, 2018. 168: p. 153-168.

444 [5] Mai, A.D., Sheikh, M.N., and Hadi, M.N., Influence of the location of CFRP strips on the 445 behaviour of partially wrapped square reinforced concrete columns under axial compression.

446 Structures, 2018. 15: p. 131-137.

447 [6] Cromwell, J., Harries, K., and Shahrooz, B., Environmental durability of externally bonded 448 FRP materials intended for repair of concrete structures. Construction and Building Materials, $449 \quad 2011.25(5):$ p. 2528-2539.

450 [7] Chen, Y., Davalos, J.F., Ray, I., and Kim, H.-Y., Accelerated aging tests for evaluations of 451 durability performance of FRP reinforcing bars for concrete structures. Composite Structures, 452 2007. 78(1): p. 101-111.

453 [8] Belarbi, A. and Bae, S.-W., An experimental study on the effect of environmental exposures 454 and corrosion on RC columns with FRP composite jackets. Composites Part B: Engineering, 2007. 455 38(5-6): p. 674-684.

456 [9] Hawileh, R.A., Abu-Obeidah, A., Abdalla, J.A., and Al-Tamimi, A., Temperature effect on the 457 mechanical properties of carbon, glass and carbon-glass FRP laminates. Construction and Building 458 Materials, 2015. 75: p. 342-348.

459 [10] Hawileh, R.A., Abdalla, J.A., Hasan, S.S., Ziyada, M.B., and Abu-Obeidah, A., Models for 460 predicting elastic modulus and tensile strength of carbon, basalt and hybrid carbon-basalt FRP 461 laminates at elevated temperatures. Construction and Building Materials, 2016. 114: p. 364-373.

462 [11] Naser, M., Hawileh, R., Abdalla, J., and Al-Tamimi, A., Bond behavior of CFRP cured 463 laminates: experimental and numerical investigation. Journal of engineering materials and 464 technology, 2012. 134(2): p. 021002. 
465 [12] Yuan, J.S. and Hadi, M.N.S., Bond-slip behaviour between GFRP I-section and concrete.

466 Composites Part B: Engineering, 2017. 130: p. 76-89.

467 [13] Choi, E., Kim, J.-W., Rhee, I., and Kang, J.-W., Behavior and modeling of confined concrete 468 cylinders in axial compression using FRP rings. Composites Part B: Engineering, 2014. 58: p. 175469184.

470 [14] El-Sayed, A.K., El-Salakawy, E., and Benmokrane, B., Mechanical and structural 471 characterization of new carbon FRP stirrups for concrete members. Journal of Composites for 472 Construction, 2007. 11(4): p. 352-362.

473 [15] Afifi, M.Z., Mohamed, H.M., Chaallal, O., and Benmokrane, B., Confinement model for 474 concrete columns internally confined with carbon FRP spirals and hoops. Journal of Structural 475 Engineering, 2014. 141(9): p. 04014219.

476 [16] Ding, L., Seliem, H.M., Rizkalla, S.H., Wu, G., and Wu, Z., Behavior of concrete piles 477 confined with CFRP grid. ACI Special Publication, 2011. 1(275): p. 189-205.

478 [17] Bentayeb, F., Tahar, K.A., and Chateauneuf, A., New technique for reinforcement of concrete 479 columns confined by embedded composite grid. Construction and Building Materials, 2008. 22(8): 480 p. $1624-1633$.

481 [18] Hawileh, R.A., Rasheed, H.A., Abdalla, J.A., and Al-Tamimi, A.K., Behavior of reinforced 482 concrete beams strengthened with externally bonded hybrid fiber reinforced polymer systems. 483 Materials \& Design, 2014. 53: p. 972-982.

484 [19] Hadi, M.N.S. and Yuan, J.S., Experimental investigation of composite beams reinforced with 485 GFRP I-beam and steel bars. Construction and Building Materials, 2017. 144: p. 462-474.

486 [20] Nanni, A., Norris, M., and Bradford, N., Lateral confinement of concrete using FRP 487 reinforcement. Special Publication, 1993. 138: p. 193-210.

488 [21] Gupta, P.K. and Verma, V.K., Study of concrete-filled unplasticized poly-vinyl chloride tubes 489 in marine environment. Proceedings of the Institution of Mechanical Engineers, Part M: Journal of 490 Engineering for the Maritime Environment, 2016. 230(2): p. 229-240. 
491 [22] Fam, A., Pando, M., Filz, G., and Rizkalla, S., Precast piles for Route 40 bridge in Virginia 492 using concrete filled FRP tubes. PCI journal, 2003. 48(3): p. 32-45.

493 [23] Sen, R. and Mullins, G., Application of FRP composites for underwater piles repair.

494 Composites Part B: Engineering, 2007. 38(5-6): p. 751-758.

495 [24] Pando, M.A., Ealy, C.D., Filz, G.M., Lesko, J., and Hoppe, E., A laboratory and field study of 496 composite piles for bridge substructures, United States. Federal Highway Administration. Office 497 of Infrastructure Research and Development, 2006.

498 [25] Kurt, C.E., Concrete filled structural plastic columns. Journal of the Structural Division, 1978. 499 104(ASCE 13478 Proceeding).

500 [26] Toutanji, H. and Saafi, M., Stress-strain behavior of concrete columns confined with hybrid 501 composite materials. Materials and Structures, 2002. 35(6): p. 338.

502 [27] Fakharifar, M. and Chen, G., Compressive behavior of FRP-confined concrete-filled PVC 503 tubular columns. Composite Structures, 2016. 141: p. 91-109.

504 [28] Ashford, S., Rollins, K., Bradford V, S., Weaver, T., and Baez, J., Liquefaction mitigation 505 using stone columns around deep foundations: Full-scale test results. Transportation Research 506 Record: Journal of the Transportation Research Board, 2000(1736): p. 110-118.

507 [29] Martin, J.B. and GR. Quantitative evaluation of stone column techniques for earthquake 508 liquefaction mitigation. in Proceedings of the Tenth World Conference on Earthquake Engineering: 509 19-24 July 1992, Madrid, Spain. 1992. CRC Press.

510 [30] Lu, J., Elgamal, A., Yan, L., Law, K.H., and Conte, J.P., Large-scale numerical modeling in 511 geotechnical earthquake engineering. International Journal of Geomechanics, 2011. 11(6): p. 490512503.

513 [31] Hugher, J. and Withers, N., Reinforcing of soft cohesive soils with stone columns. Ground 514 engineering, 1974. 7(3), 42-49.

515 [32] Juran, I. and Guermazi, A., Settlement response of soft soils reinforced by compacted sand 516 columns. Journal of Geotechnical Engineering, 1988. 114(8): p. 930-943. 
517 [33] Cimentada, A., Da Costa, A., Cañizal, J., and Sagaseta, C., Laboratory study on radial 518 consolidation and deformation in clay reinforced with stone columns. Canadian Geotechnical 519 Journal, 2010. 48(1): p. 36-52.

520 [34] Suleiman, M.T., Ni, L., and Raich, A., Development of pervious concrete pile ground-

521 improvement alternative and behavior under vertical loading. Journal of Geotechnical and

522 Geoenvironmental Engineering, 2014. 140(7): p. 04014035.

523 [35] Lin, H., Suleiman, M.T., Jabbour, H.M., Brown, D.G., and Kavazanjian Jr, E., Enhancing the

524 Axial Compression Response of Pervious Concrete Ground Improvement Piles Using Biogrouting.

525 Journal of Geotechnical and Geoenvironmental Engineering, 2016. 142(10): p. 04016045.

526 [36] Wang, W., Sheikh, M.N., and Hadi, M.N.S., Axial compressive behaviour of concrete

527 confined with polymer grid. Materials and Structures, 2016. 49(9): p. 3893-3908.

528 [37] Davidovits, J., High-alkali cements for 21 st century concretes. Special Publication, 1994. 144:

529 p. 383-398.

530 [38] Sata, V., Wongsa, A., and Chindaprasirt, P., Properties of pervious geopolymer concrete using 531 recycled aggregates. Construction and Building materials, 2013. 42: p. 33-39.

532 [39] Tho-in, T., Sata, V., Chindaprasirt, P., and Jaturapitakkul, C., Pervious high-calcium fly ash 533 geopolymer concrete. Construction and Building Materials, 2012. 30: p. 366-371.

534 [40] Australasian Slag Association, 41-47 Five Islands Road, Port Kembla, NSW, Australia, 535 accessed on June 2018: http://www.asa-inc.org.au/products/ground-granulated-blast-furnace-slag. 536 [41] Eraring power station, Australia, 227 Elizabeth Street, Sydney, NSW, Australia, accessed on 537 June 2018: https://www.originenergy.com.au/about/who-we-are/what-we-do/generation.html.

538 [42] Standards Australia, AS 3582.1. Supplementary cementitious materials Part 1: Fly ash. 2016, 539 Sydney: Standards Australia.

540 [43] Standards Australia, AS 1012.9. Methods for testing concrete Method 9: Compressive strength 541 tests - Concrete, mortar and grout specimens. 2014, Sydney: Standards Australia. 
542 [44] Aoki, Y., Sri Ravindrarajah, R., and Khabbaz, H., Properties of pervious concrete containing

543 fly ash. Road materials and pavement design, 2012. 13(1): p. 1-11.

544 [45] American Society for Testing and Materials, ASTM D6637-M15. Standard test method for

545 determining tensile properties of geogrids by the single or multi-rib tensile method. 2015, West

546 Conshohocken, PA, USA: American Society for Testing and Materials.

547 [46] American Society for Testing and Materials, ASTM D7565/D7565M-10 Standard test method

548 for determining tensile properties of fiber reinforced polymer matrix composite used for

549 strengthening of civil structures. 2010, West Conshohocken, PA, USA: American Society for

550 Testing and Materials.

551 [47] American Society for Testing and Materials, ASTM D638-14. Standard test method for tensile

552 properties of plastics. 2014, West Conshohocken, PA, USA: American Society for Testing and

553 Materials.

554 [48] Teng, J., Jiang, T., Lam, L., and Luo, Y., Refinement of a design-oriented stress-strain model

555 for FRP-confined concrete. Journal of Composites for Construction, 2009. 13(4): p. 269-278.

556 [49] Jiang, T. and Teng, J., Analysis-oriented stress-strain models for FRP-confined concrete.

557 Engineering Structures, 2007. 29(11): p. 2968-2986.

558 [50] Raithel, M., Küster, V., and Lindmark, A. Geotextile-Encased Columns-a foundation system

559 for earth structures, illustrated by a dyke project for a works extension in Hamburg. in Nordic

560 Geotechnical Meeting NGM. 2004. Citeseer.

561 [51] Park, R., Evaluation of ductility of structures and structural assemblages from laboratory

562 testing. Bulletin of the New Zealand national society for earthquake engineering, 1989. 22(3): p.

563 155-166.

564

565 


\section{List of Figures}

567 Fig. 1. Details of FPCC samples (units: mm; SG: strain gauge).

568 Fig. 2. GPGCPs without and with FPCC: (a) GPGCPs without FPCC; (b) GPGCPs with FPCC.

569 Fig. 3. Details of GPGCP specimens (units: mm; SG: strain gauge): (a) GG1, GG2, GG3; (b) GGC1,

570 GGC2, GGC3.

571 Fig. 4. Geogrid used in this study: (a) uniaxial geogrid; (b) Tensile load-axial strain curves of the 572 geogrid coupons.

573 Fig. 5. Tensile test of the GFRP coupons.

574 Fig. 6. PVC coupons used in this study: (a) dog-bone PVC coupon; (b) tensile load-axial strain 575 curves of the PVC coupons.

576 Fig. 7. Axial load-axial strain curves of PGC and NGC.

577 Fig. 8. FRP-PVC tubes: (a) failure mode of the FRP-PVC; (b) axial load-axial strain curves.

578 Fig. 9. Failure mode of the FRP-PVC-confined concrete.

579 Fig. 10. Axial stress-axial strain curves of FPCC.

580 Fig. 11. Axial-hoop strain responses of FPCC.

581 Fig. 12. Final state of the representative GPGCPs without FPCC: (a) GG1; (b) GG2; (c) GG3.

582 Fig. 13. Final state of the representative GPGCPs with FPCC: (a) GGC1; (b) GGC2; (c) GGC3.

583 Fig. 14. Axial stress-axial strain curves of GPGCPs without FPCC.

584 Fig. 15. Axial-hoop strain responses of GPGCPs without FPCC.

585 Fig. 16. Axial stress-axial strain curves of GPGCPs with FPCC

586 Fig. 17. Axial-hoop strain responses of GPGCPs with FPCC

587 Fig. 18. Axial-hoop strain responses of FPCC placed in GPGCPs.

588 Fig. 19. Comparisons between GG1 and GGC1.

589 Fig. 20. Comparisons between GG2 and GGC2.

590 Fig. 21. Comparisons between GG3 and GGC3. 
591 Fig. 22. Definition of $\varepsilon_{u}$ and $\varepsilon_{y}$ : (a) Definition of $\varepsilon_{u}$ and $\varepsilon_{y}$ for unconfined concrete; (b) Definition

592 of $\varepsilon_{u}$ and $\varepsilon_{y}$ for GPGCPs without FPCC; (c) Definition of $\varepsilon_{u}$ and $\varepsilon_{y}$ for GPGCPs with FPCC 

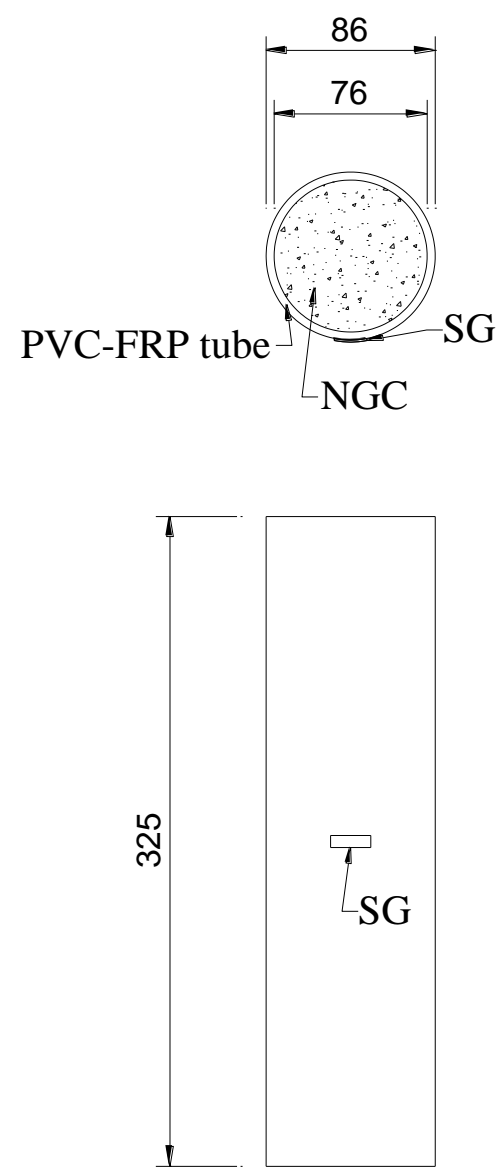

594

595

Fig. 1. Details of FPCC samples (units: mm; SG: strain gauge).

596 


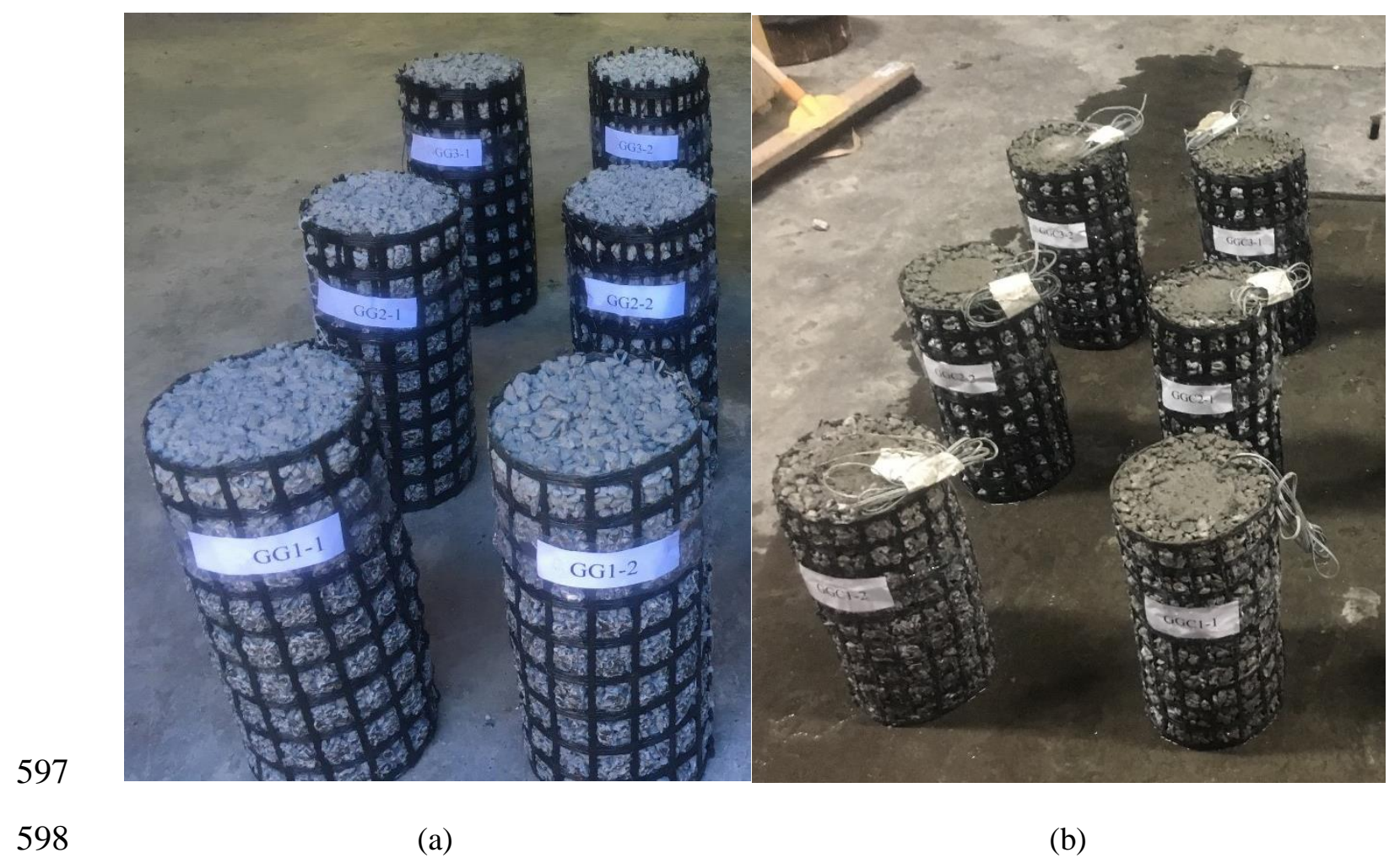

599 Fig. 2. GPGCPs without and with FPCC: (a) GPGCPs without FPCC; (b) GPGCPs with FPCC. 600 

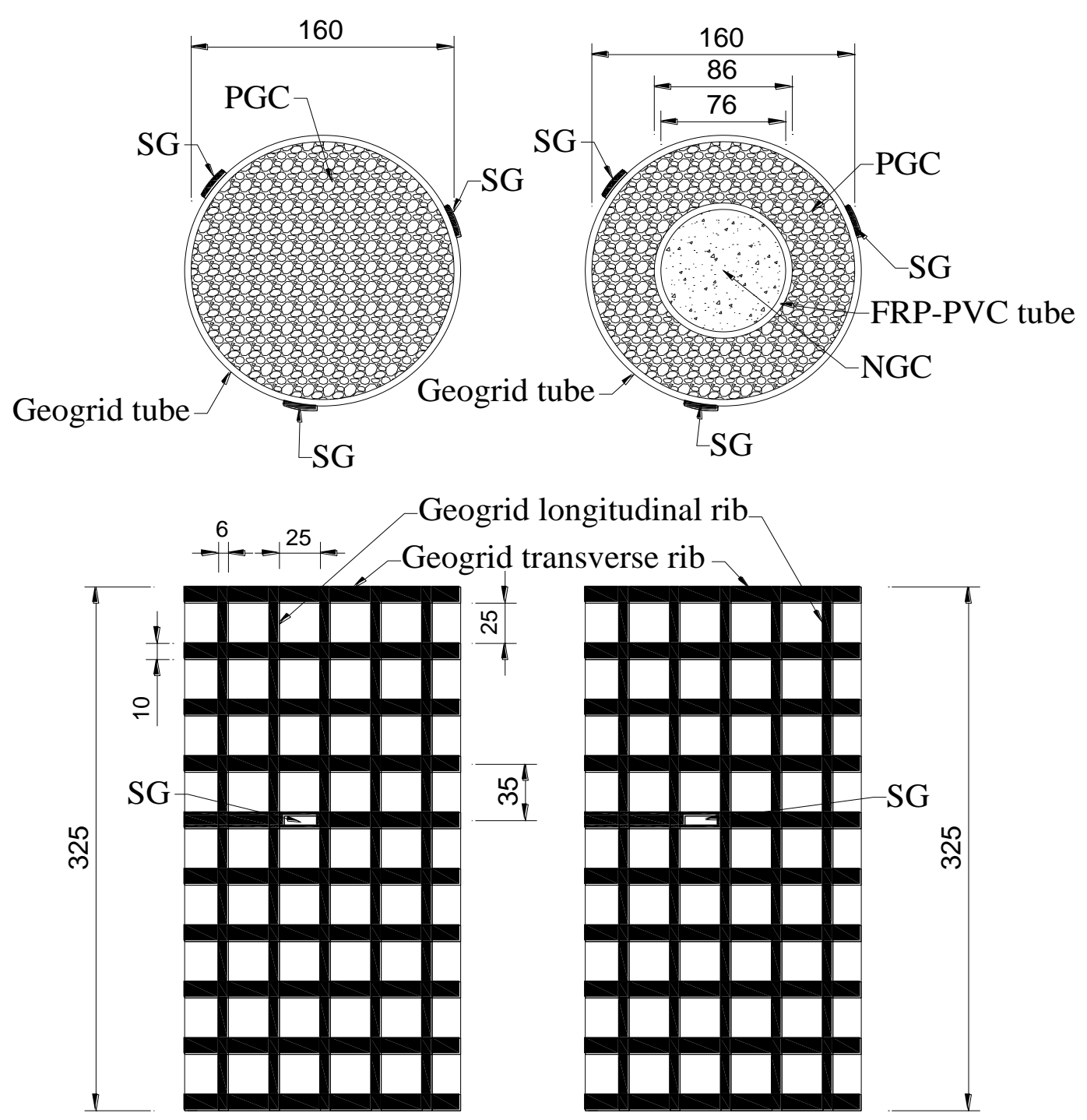

601

602

(a)

(b)

603

604

605
Fig. 3. Details of GPGCP specimens (units: mm; SG: strain gauge): (a) GG1, GG2, GG3; (b) GGC1, GGC2, GGC3. 


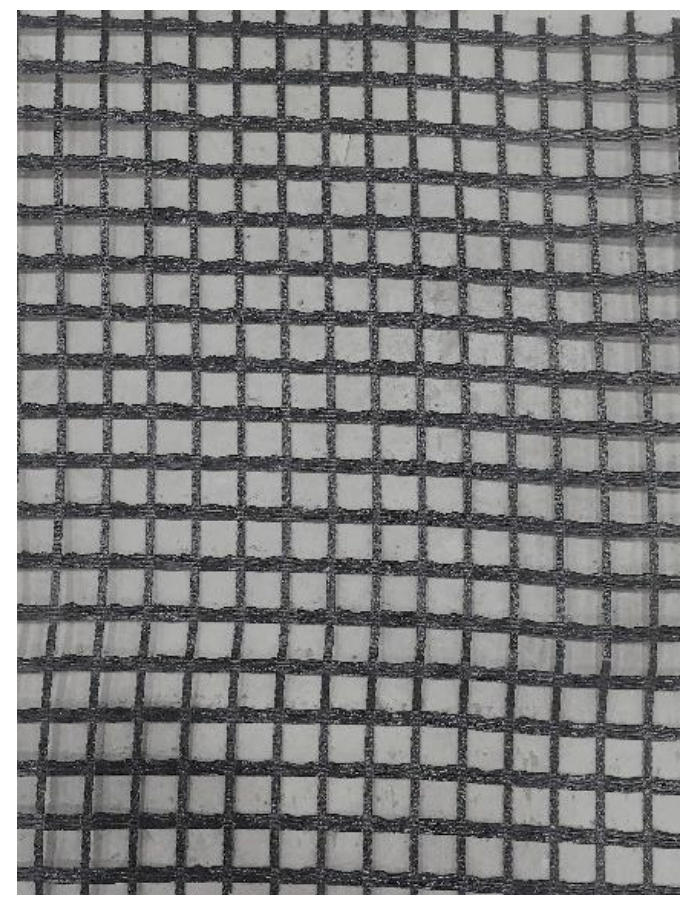

(a)

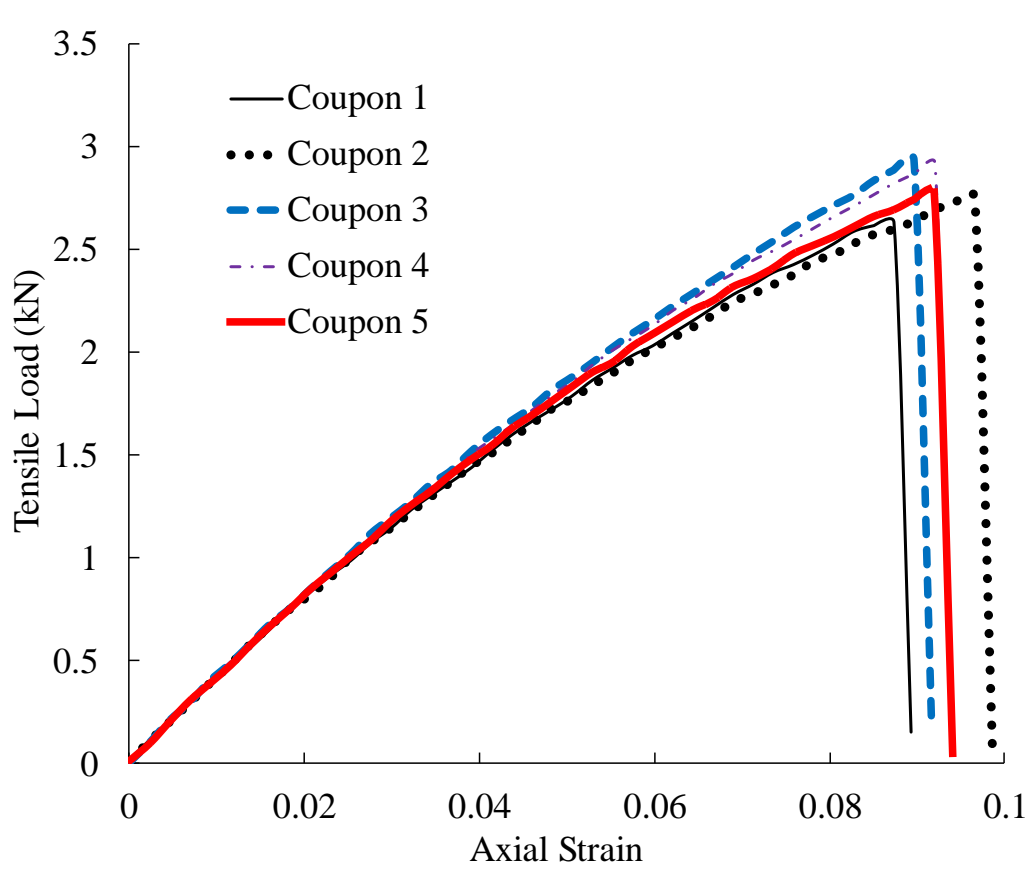

610 Fig. 4. Geogrid used in this study: (a) Uniaxial geogrid; (b) Tensile load-axial strain curves of the 611 geogrid coupons. 


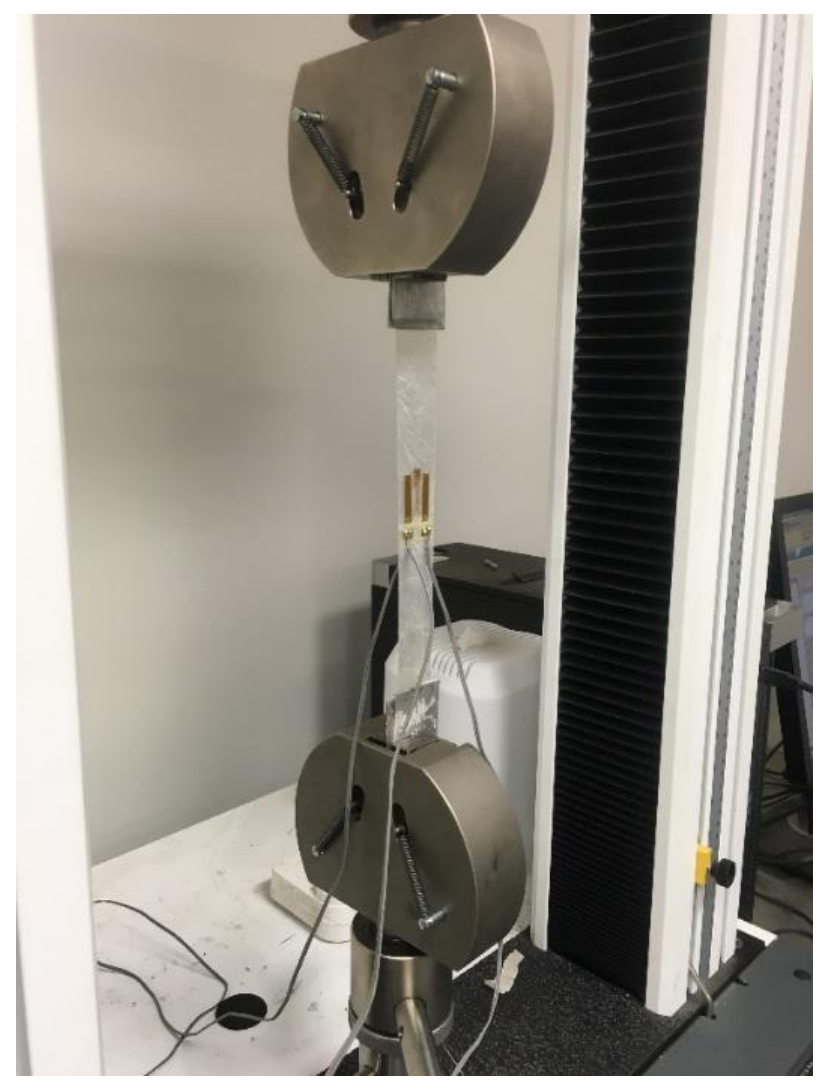

613

Fig. 5. Tensile test of the GFRP coupons.

614 


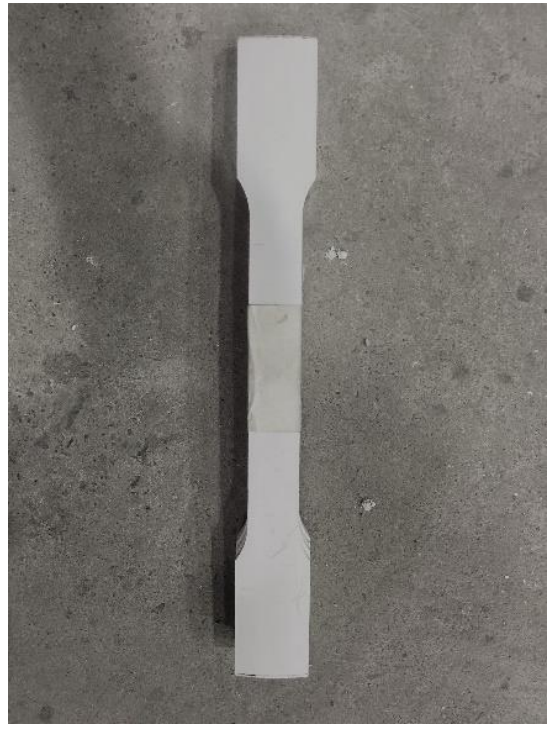

(a)

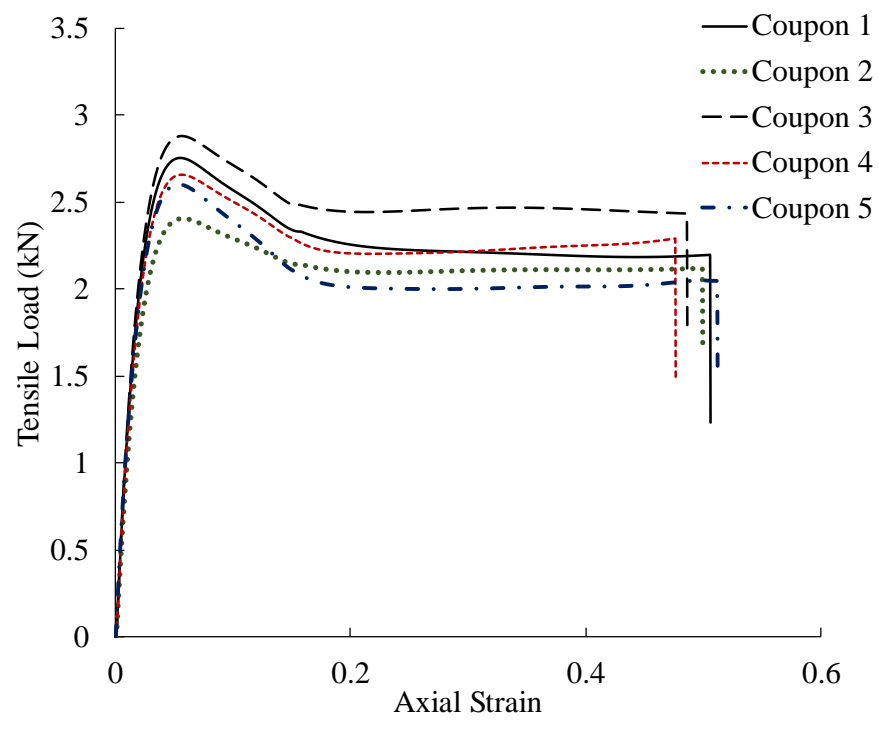

(b)

617 Fig. 6. PVC coupons used in this study: (a) Dog-bone PVC coupon; (b) Tensile load-axial strain 618 curves of the PVC coupons.

619 


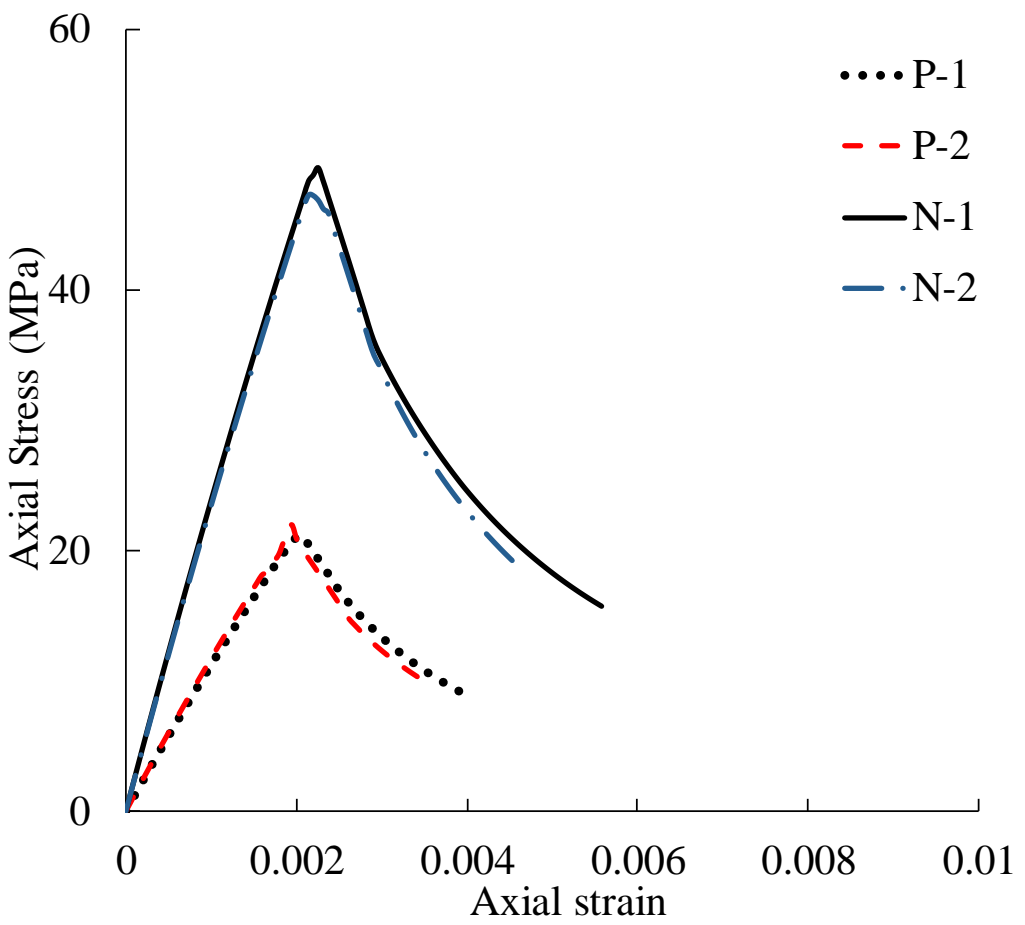

Fig. 7. Axial load-axial strain curves of PGC and NGC. 


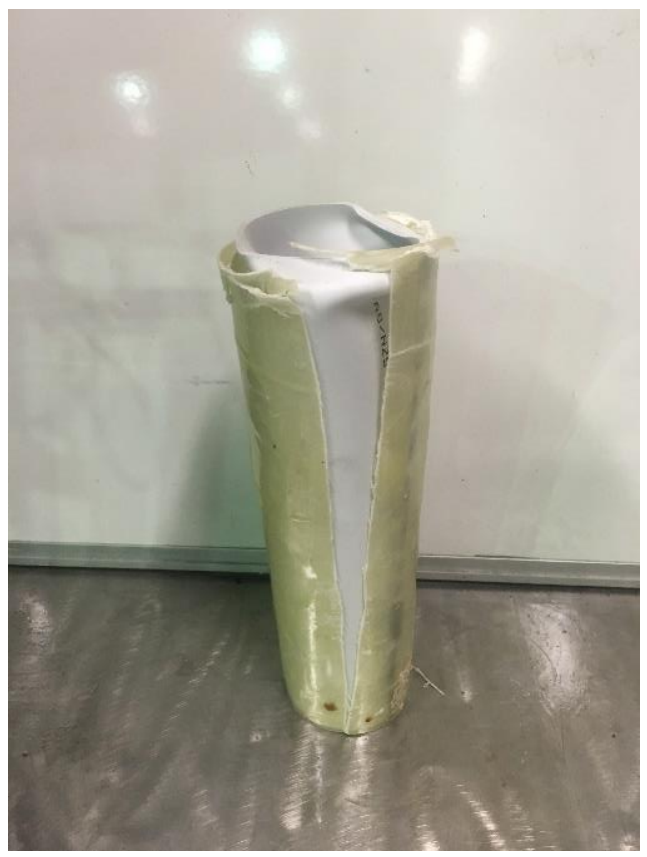

(a)

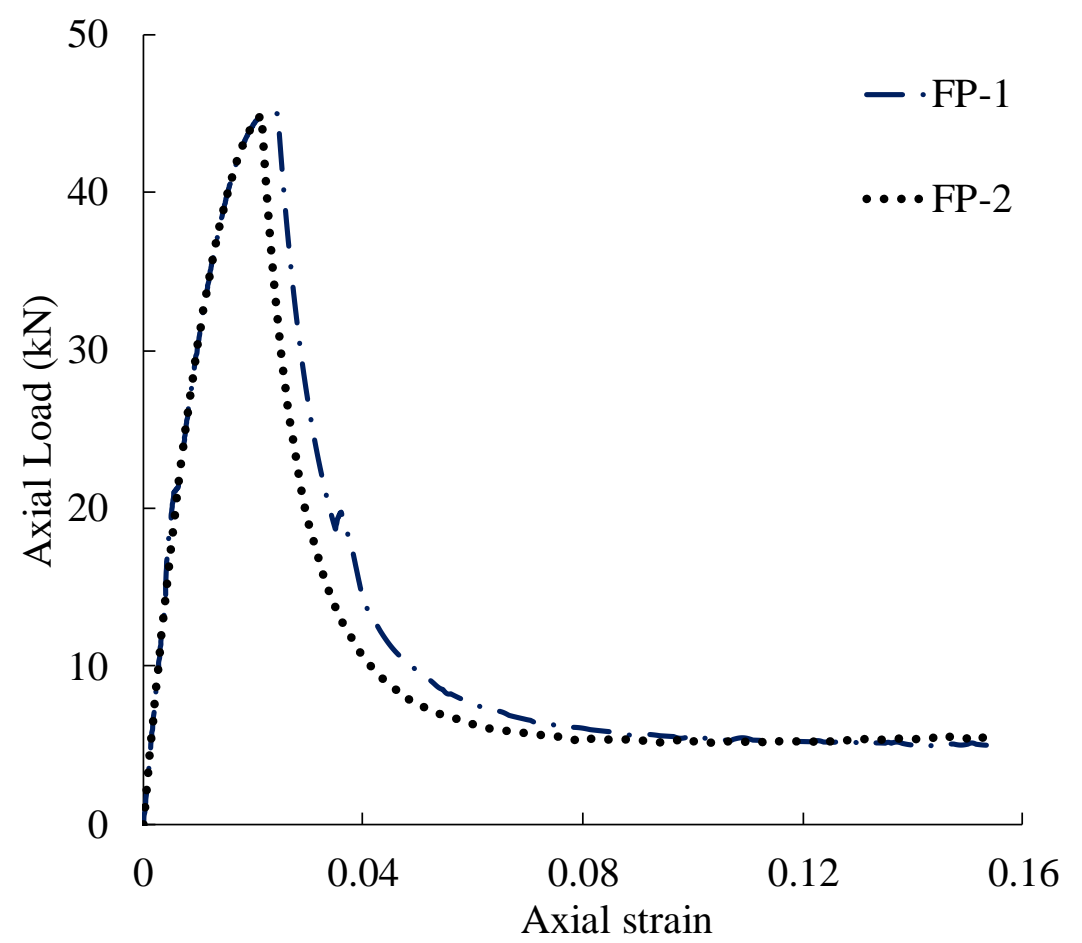

(b)

626 Fig. 8. FRP-PVC tubes: (a) Failure mode of the FRP-PVC hollow tube; (b) Axial load-axial strain 627 curves. 


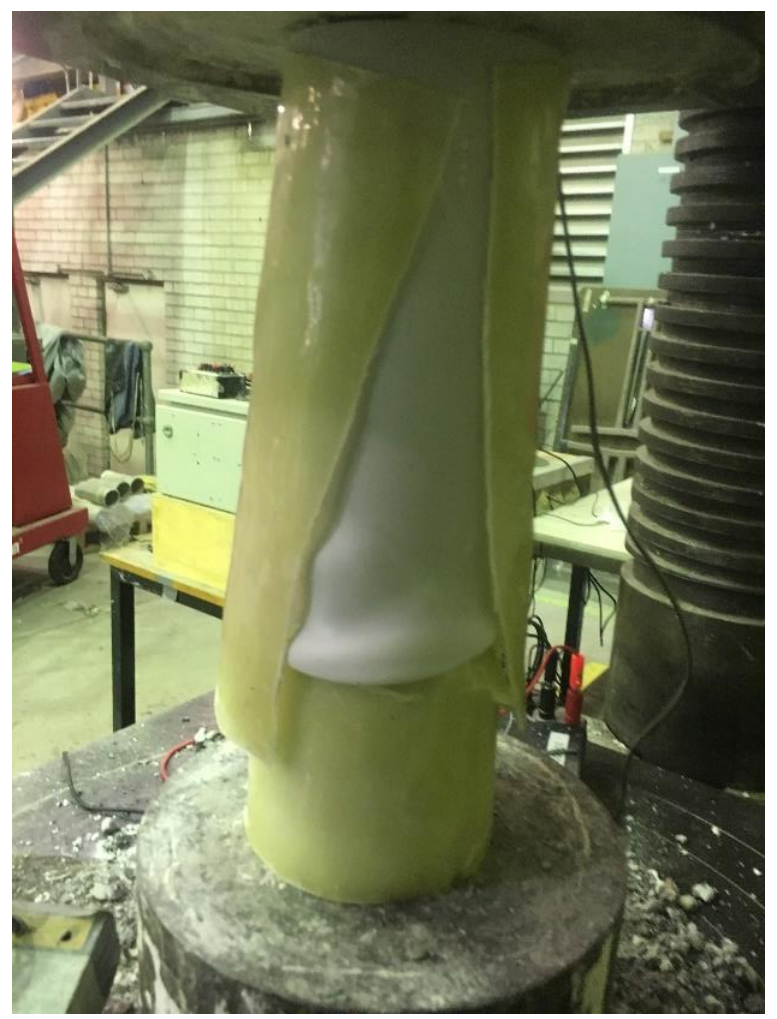

629

Fig. 9. Failure mode of the FRP-PVC-confined concrete.

630 


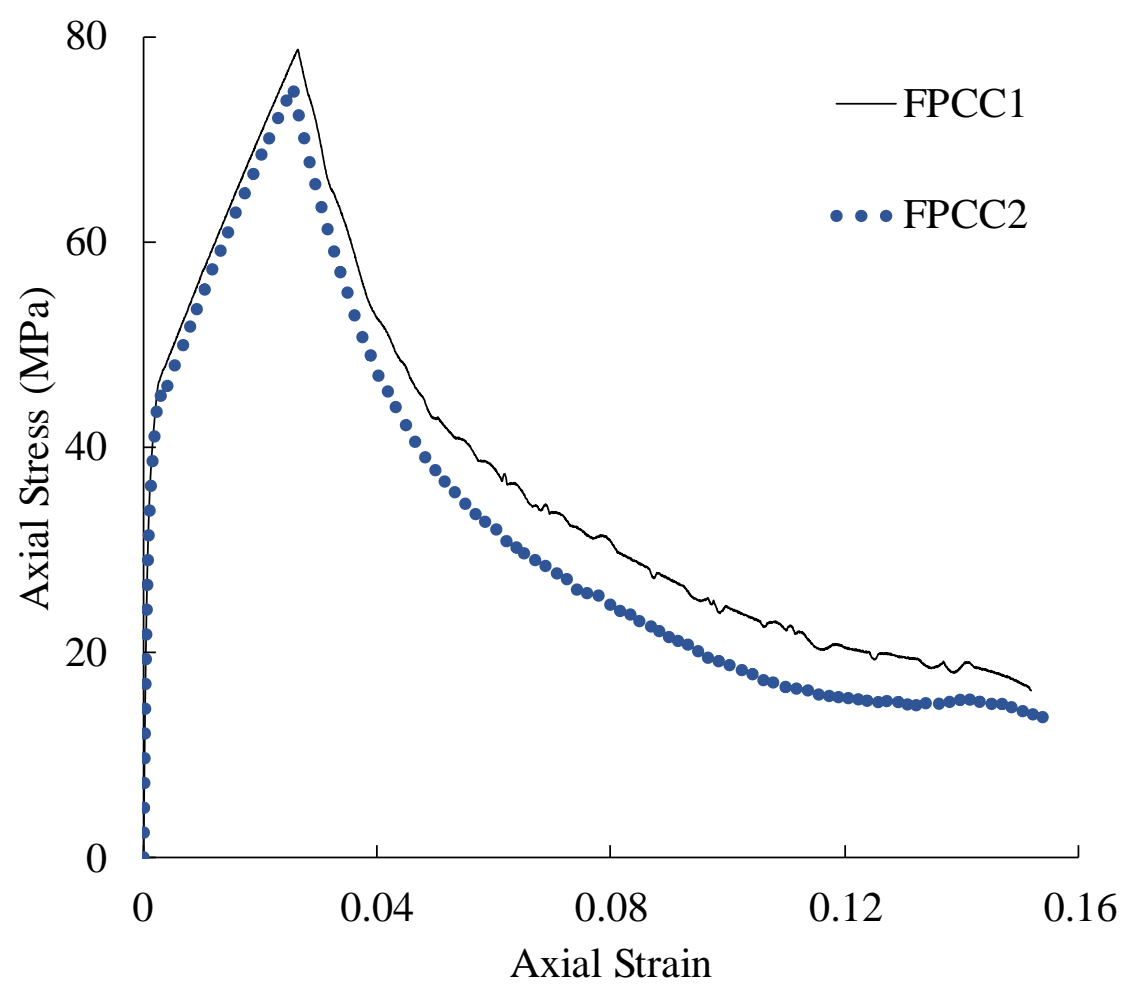

632

633

Fig. 10. Axial stress-axial strain curves of the FPCCs. 


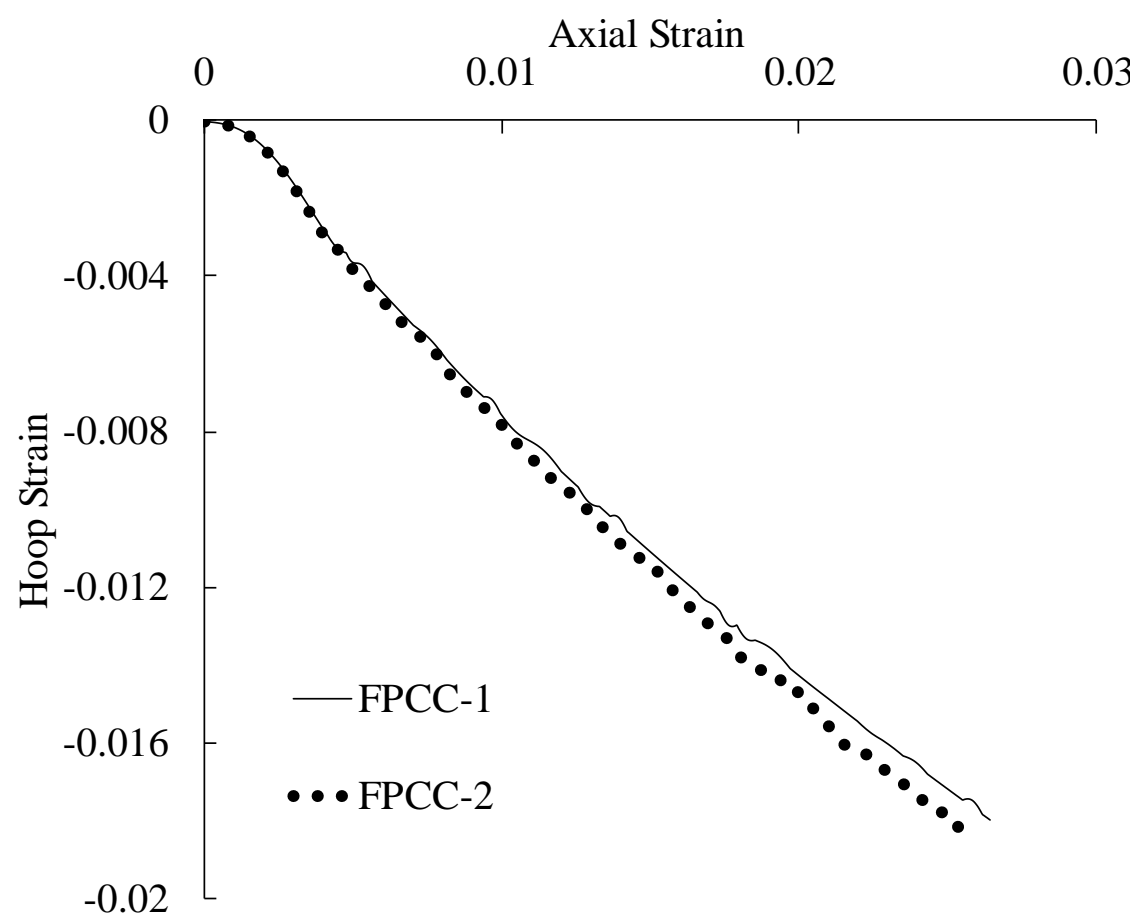

634

635

636

Fig. 11. Axial-hoop strain responses of the FPCCs. 


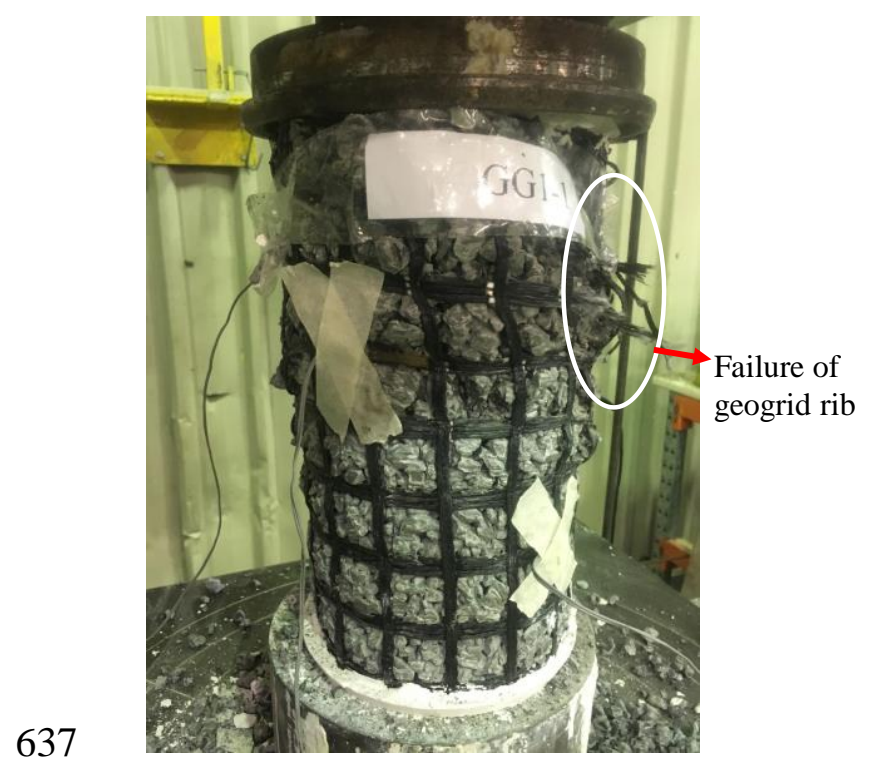

638

(a)

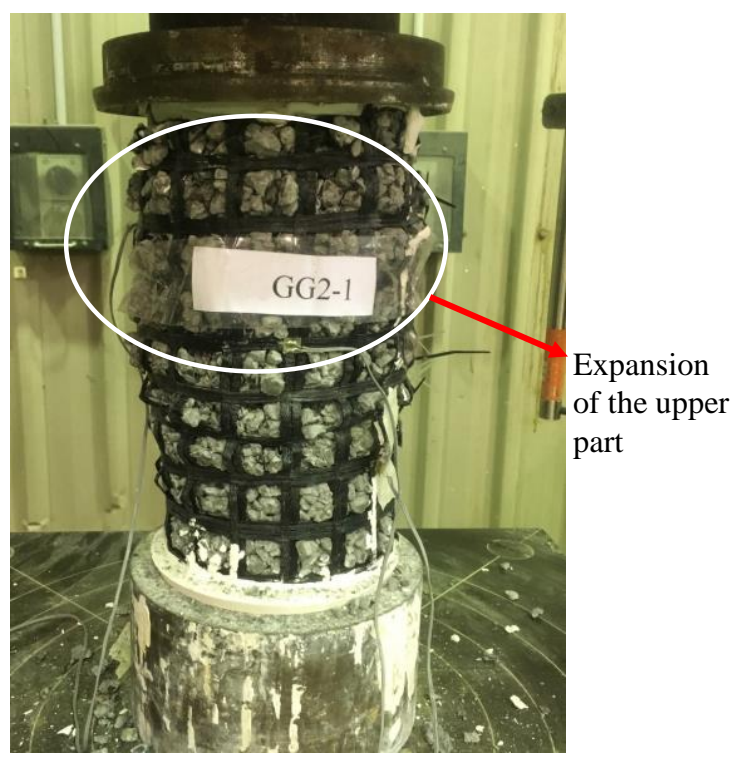

(b)

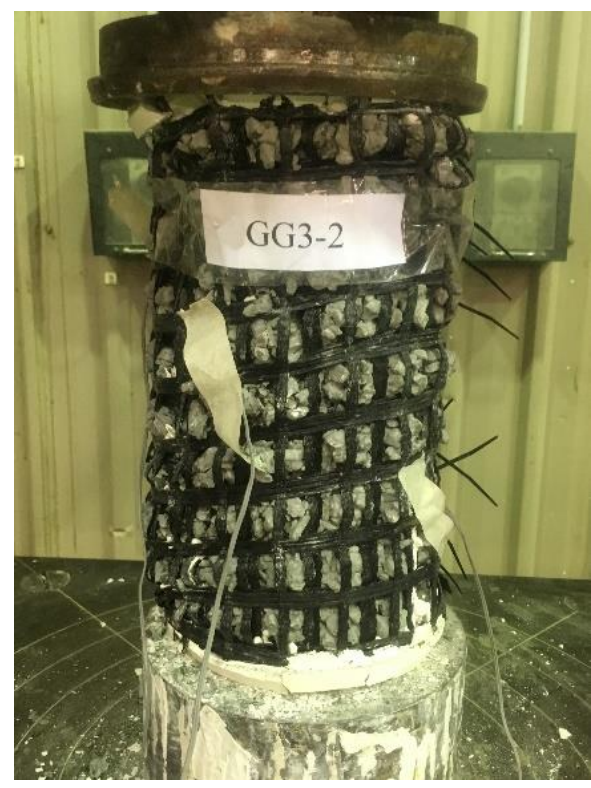

(c)

Fig. 12. Final state of the representative GPGCPs without FPCC: (a) GG1-1;

(b) GG2-1; (c) GG3-2. 


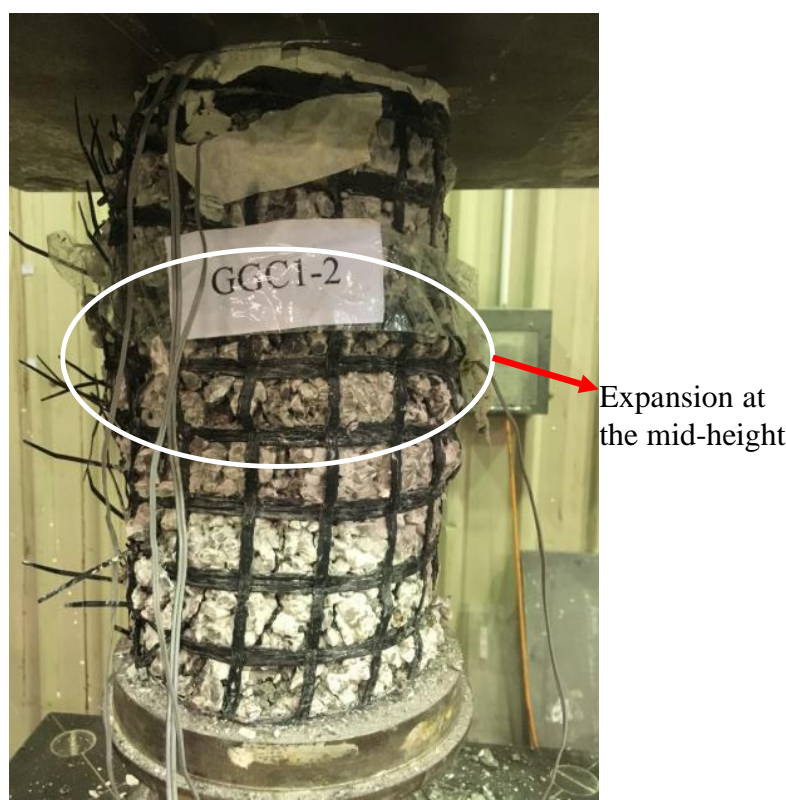

645

(a)

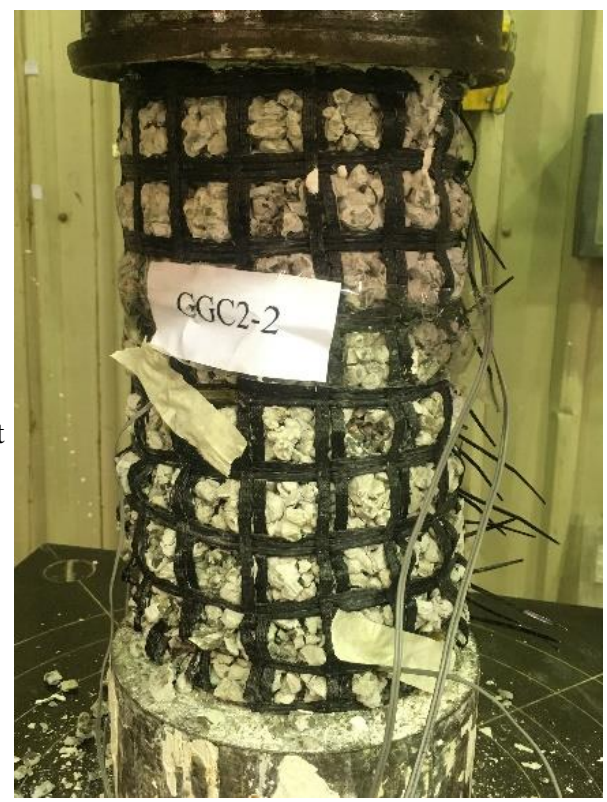

(b)

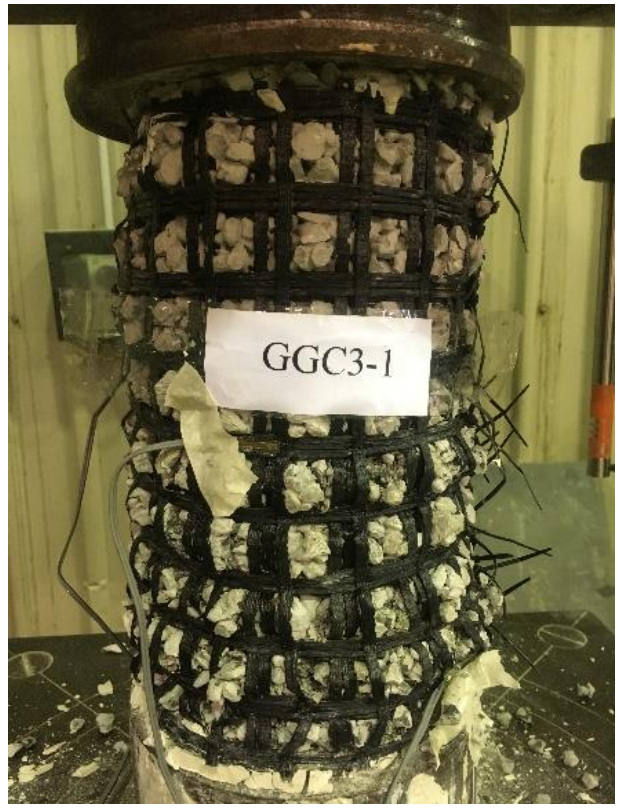

648 Fig. 13. Final state of the representative GPGCPs with FPCC: (a) GGC1-2; (b) GGC2-2; (c) 649 GGC3-1. 


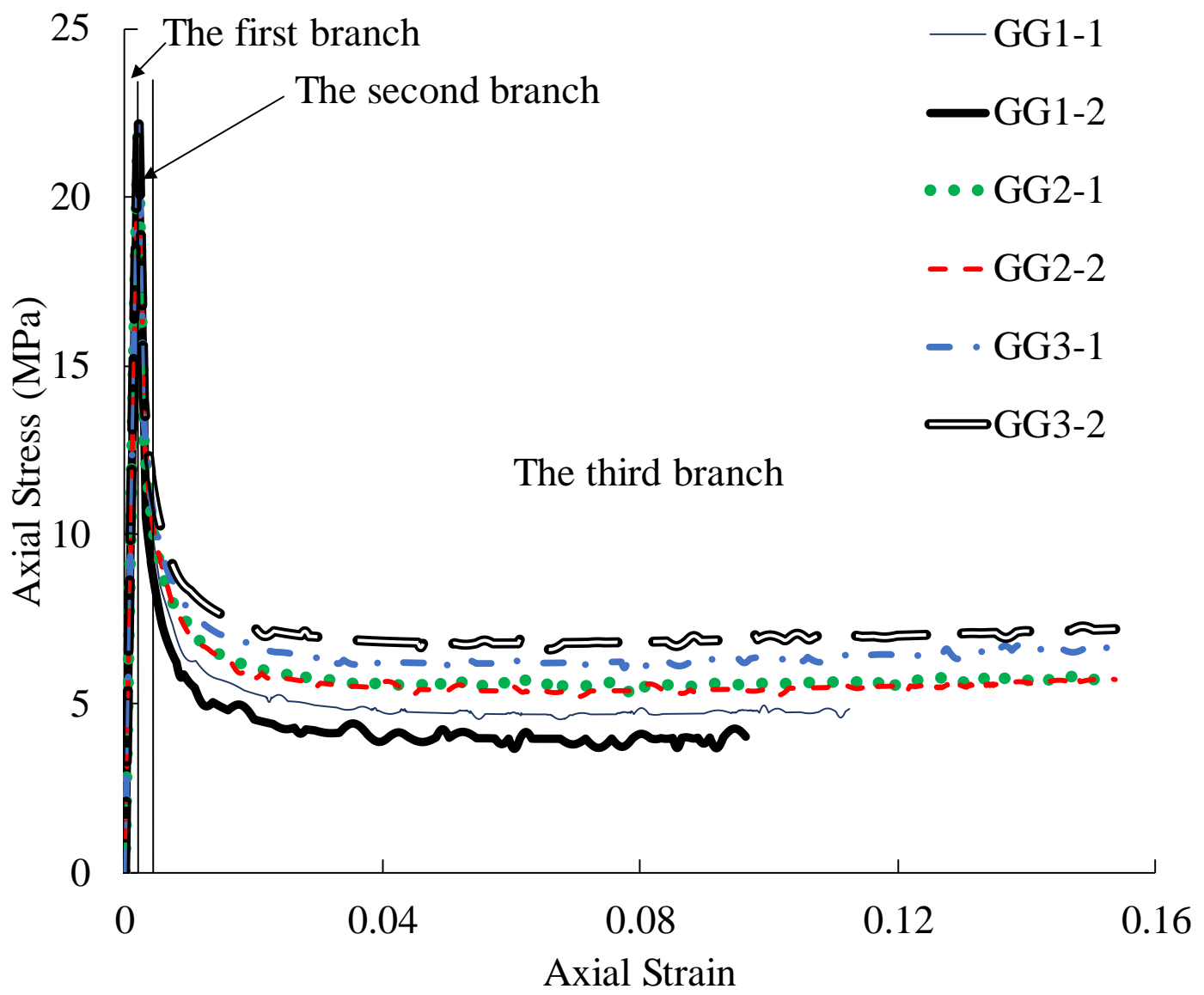

Fig. 14. Axial stress-axial strain curves of GPGCPs without FPCC. 


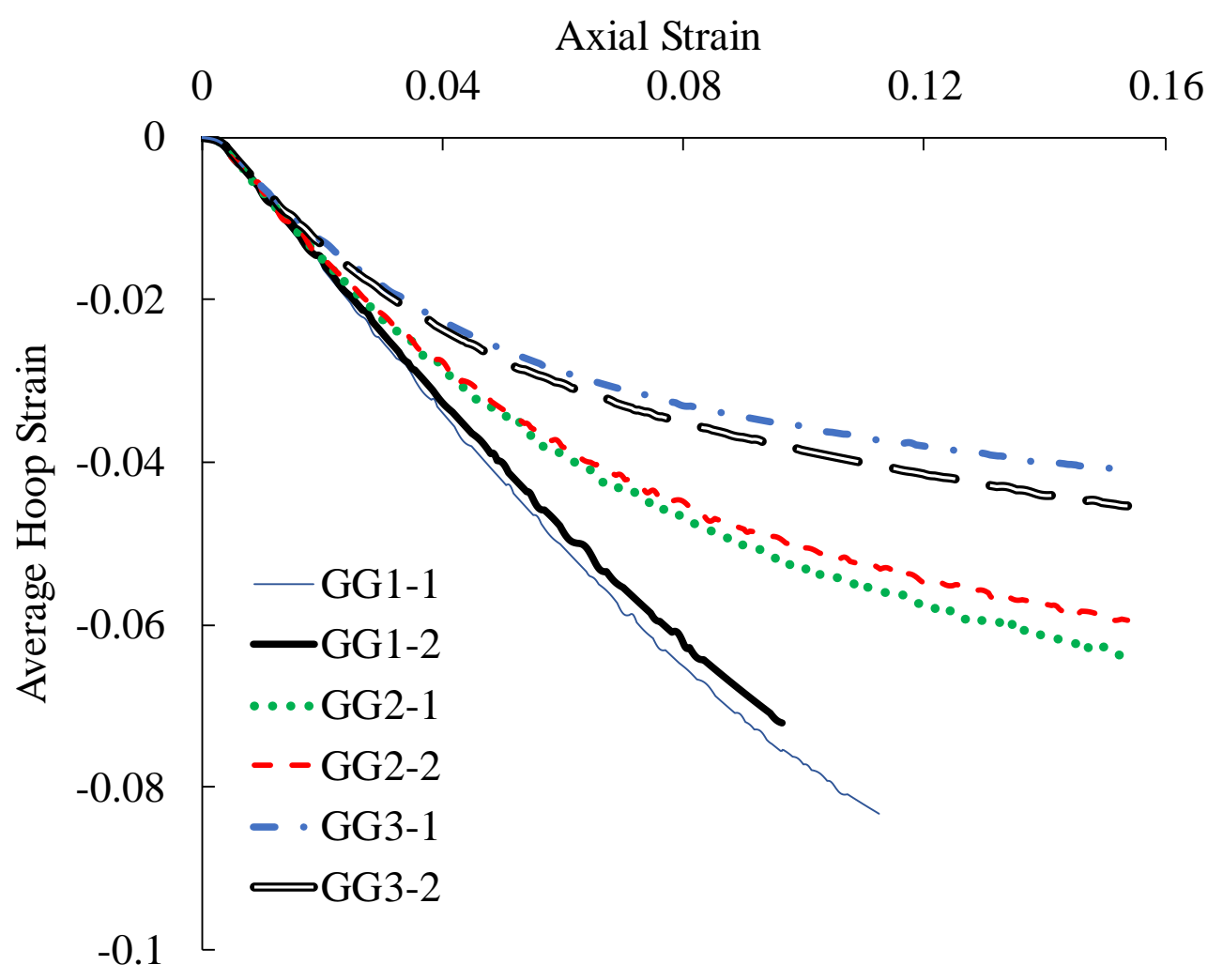

Fig. 15. Axial-hoop strain responses of GPGCPs without FPCC. 


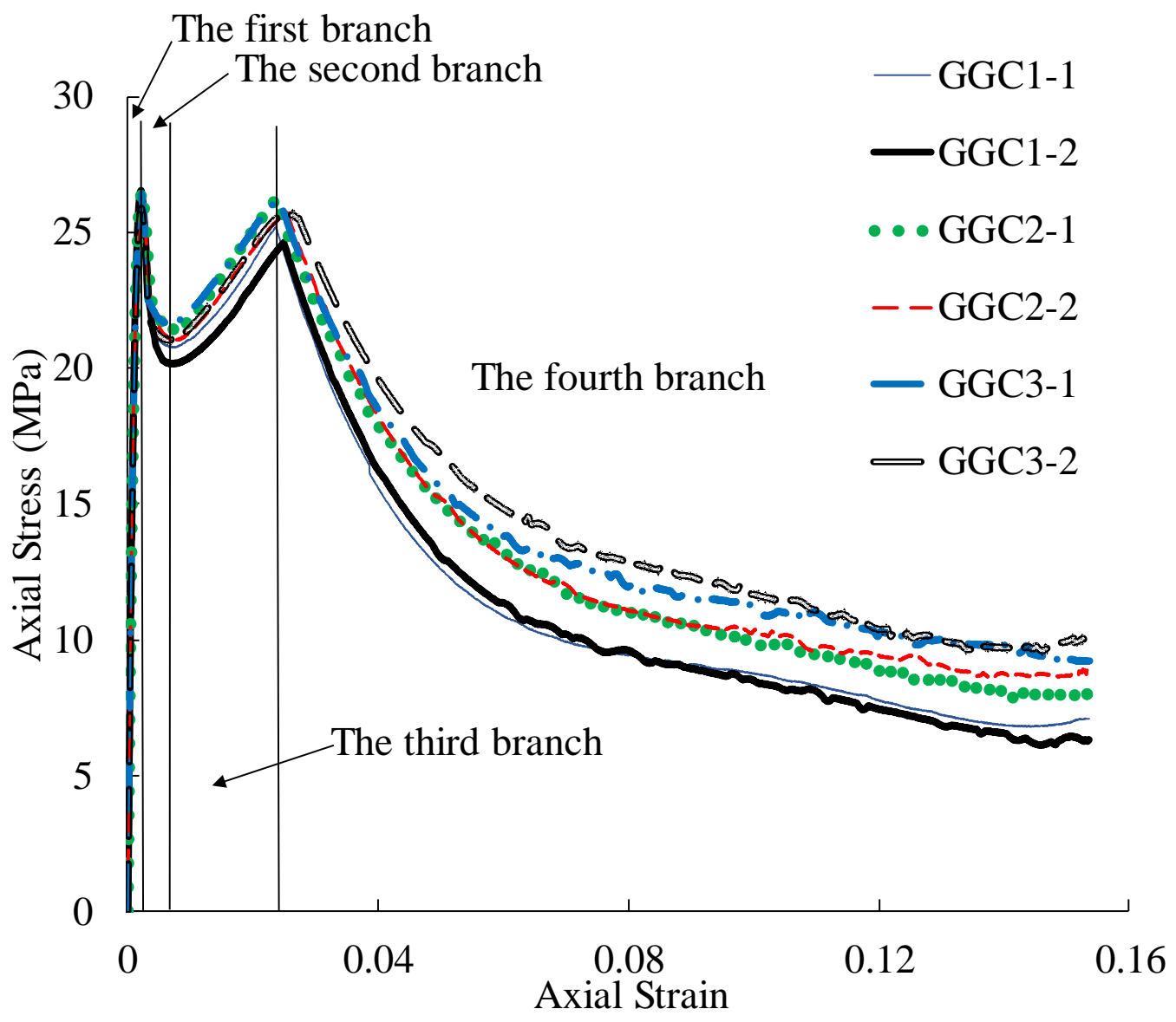

658

659

Fig. 16. Axial stress-axial strain curves of GPGCPs with FPCC. 


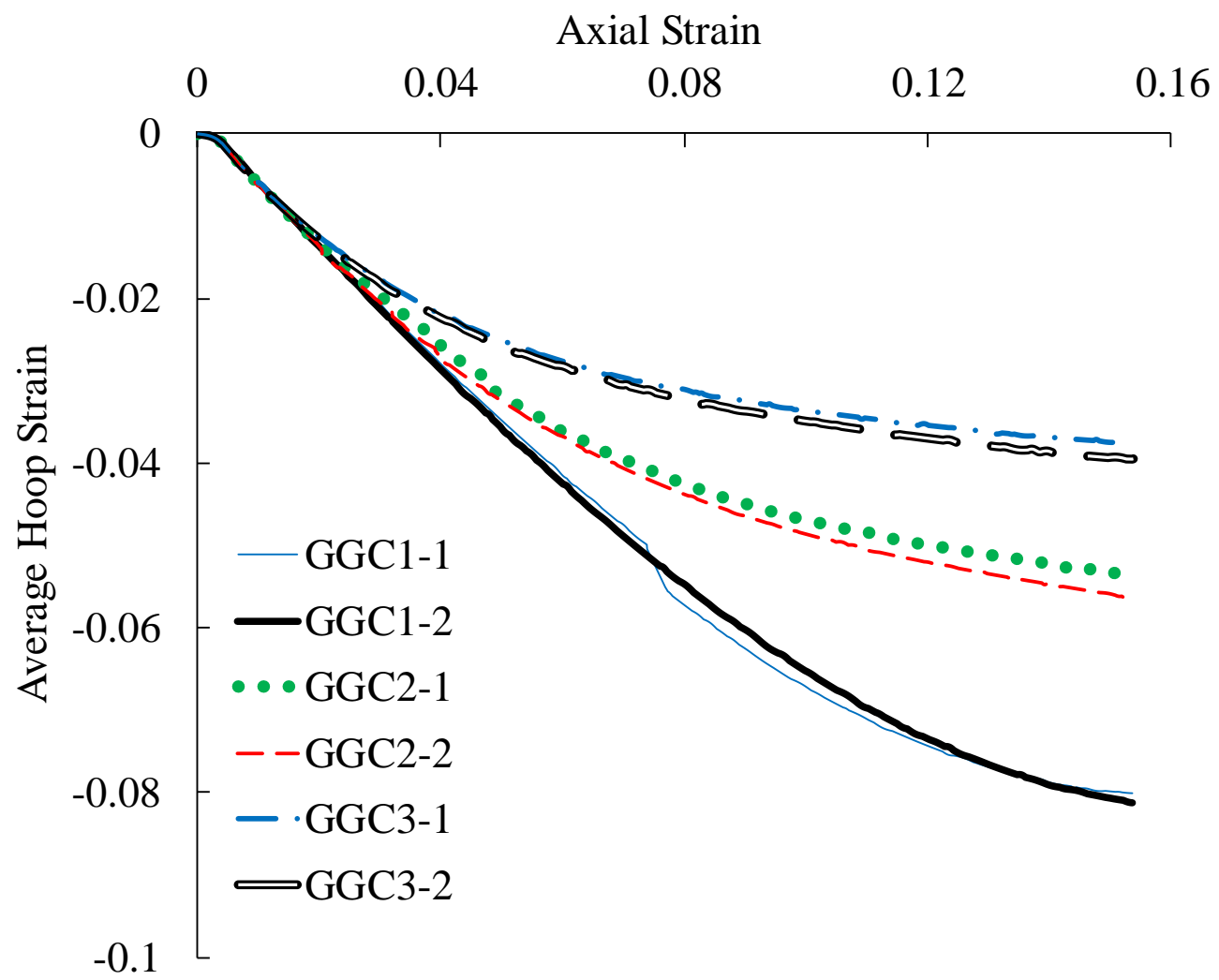

Fig. 17. Axial-hoop strain responses of GPGCPs with FPCC.

662 


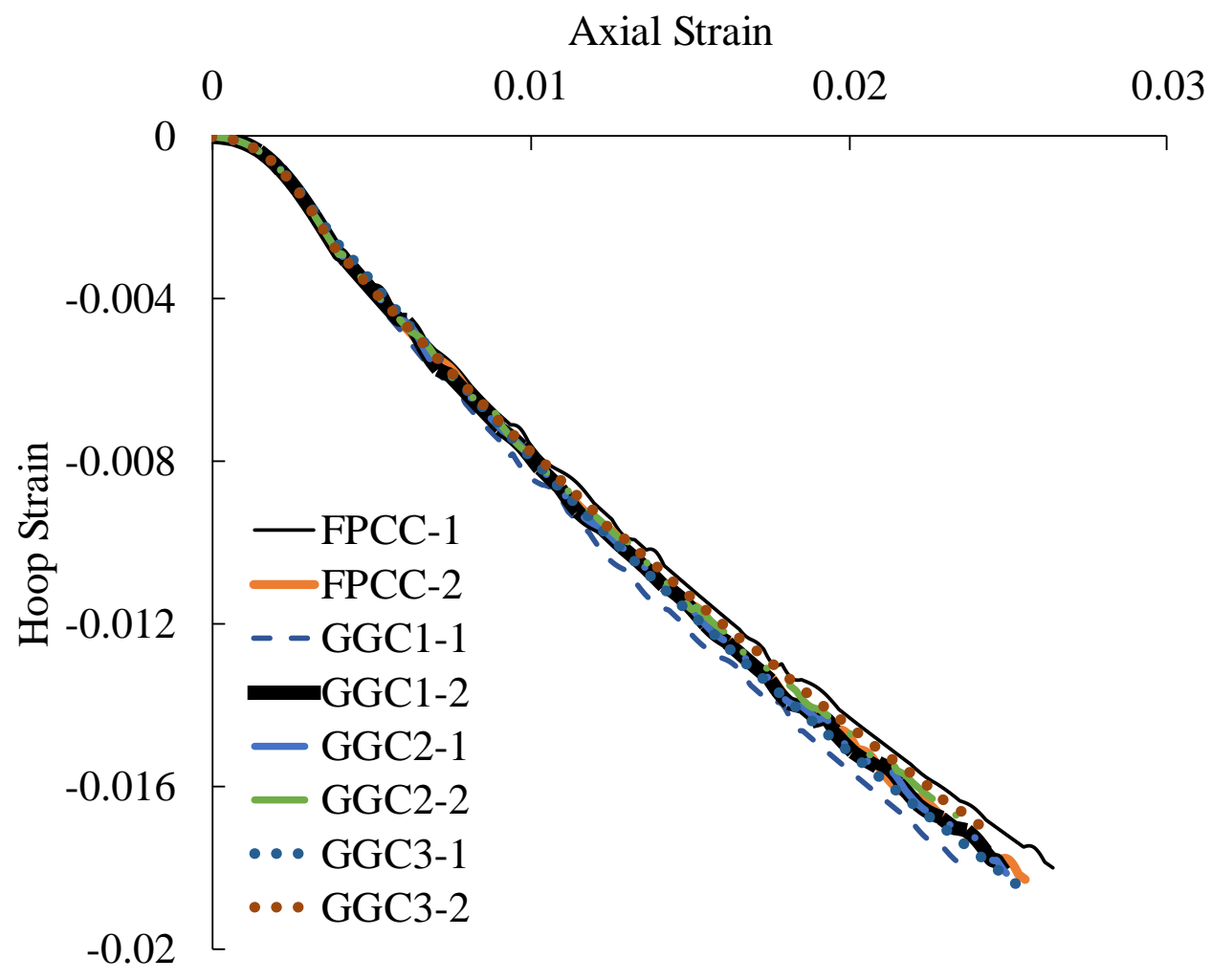

663

664

Fig. 18. Axial-hoop strain responses of FPCC placed in GPGCPs.

665 
666

667
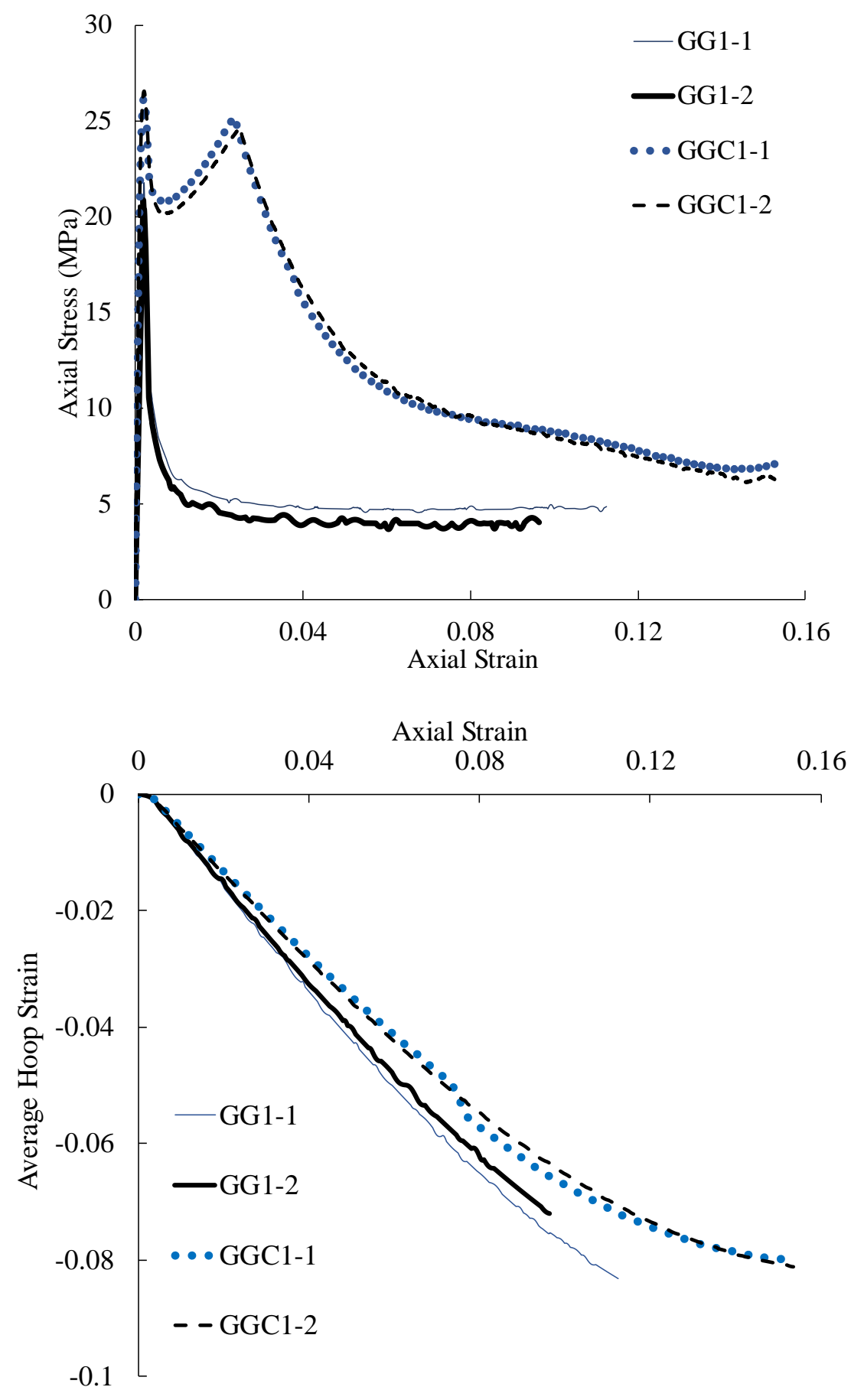

668

669

670

Fig. 19. Comparisons between GG1 and GGC1. 

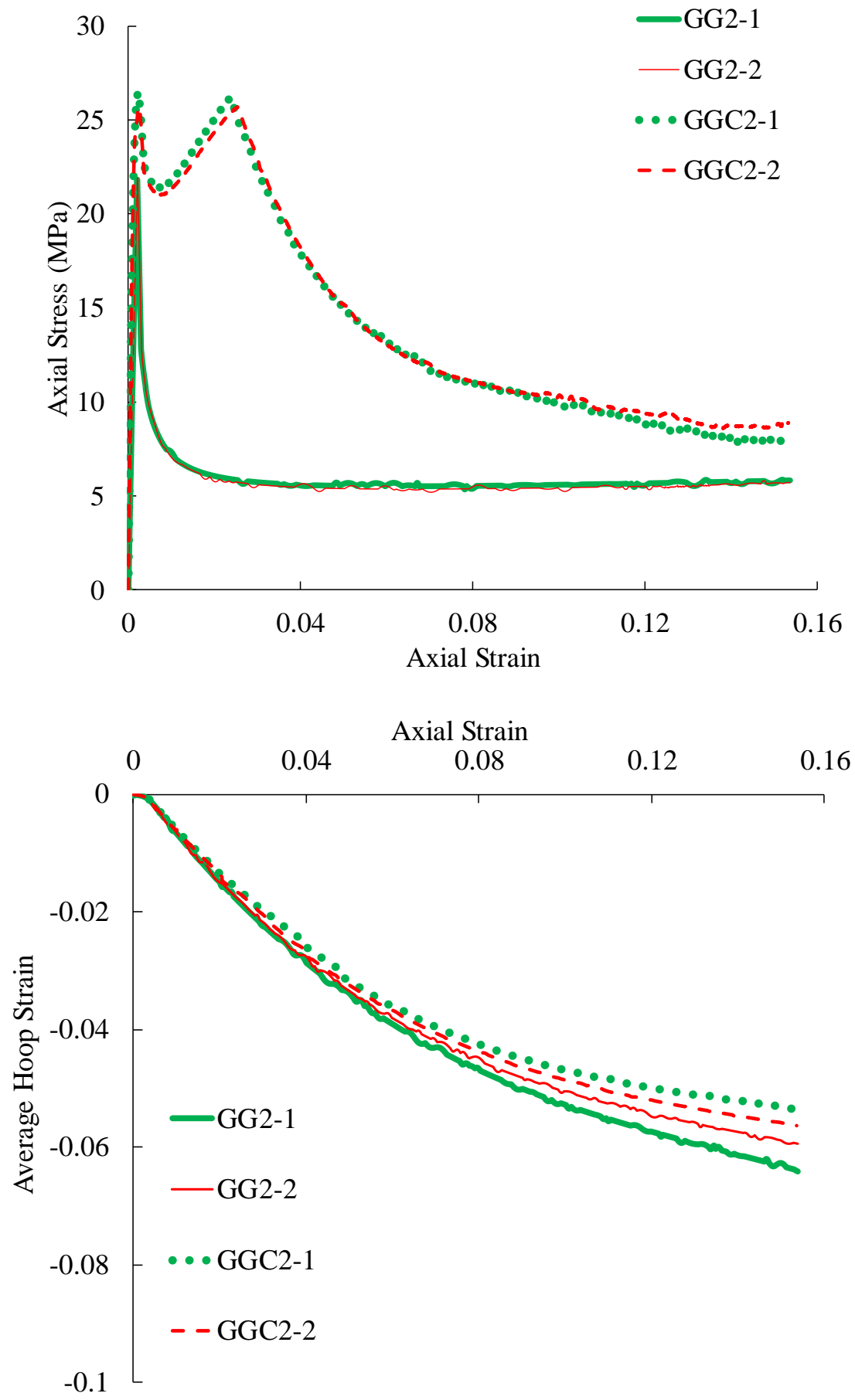

672

673

674

Fig. 20. Comparisons between GG2 and GGC2. 


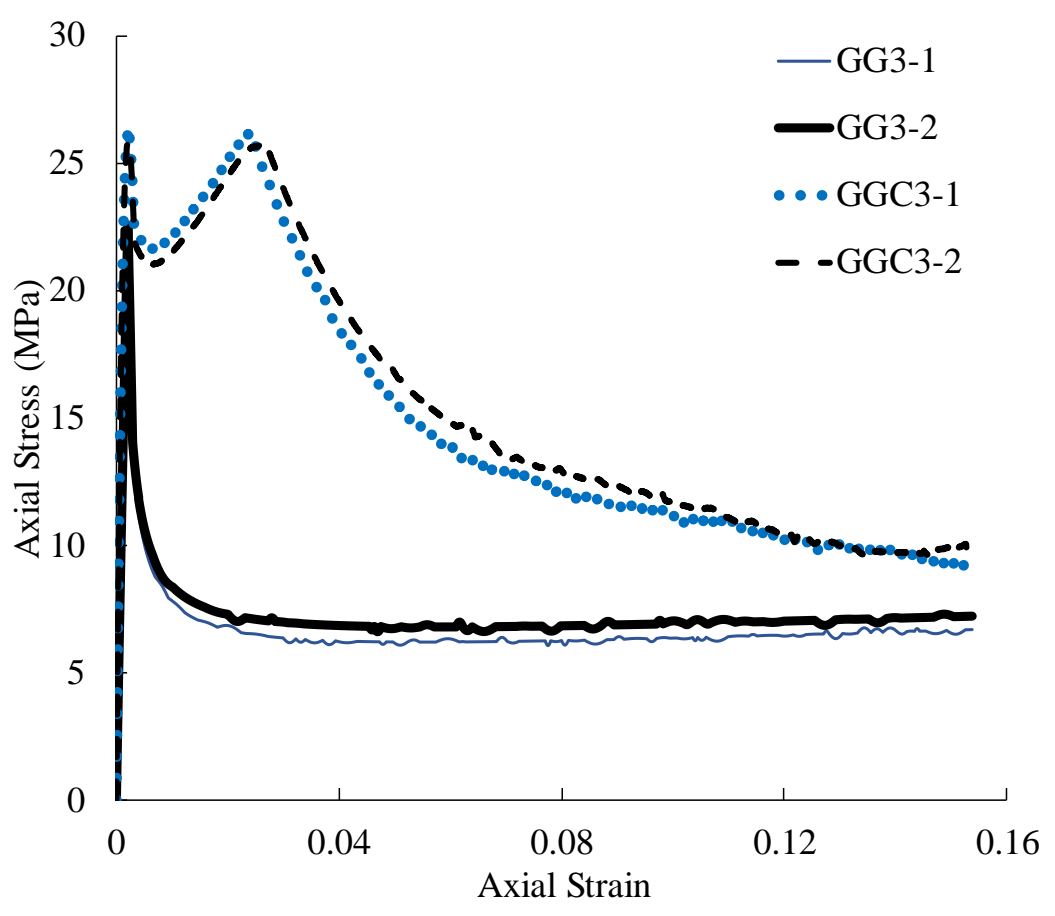

675

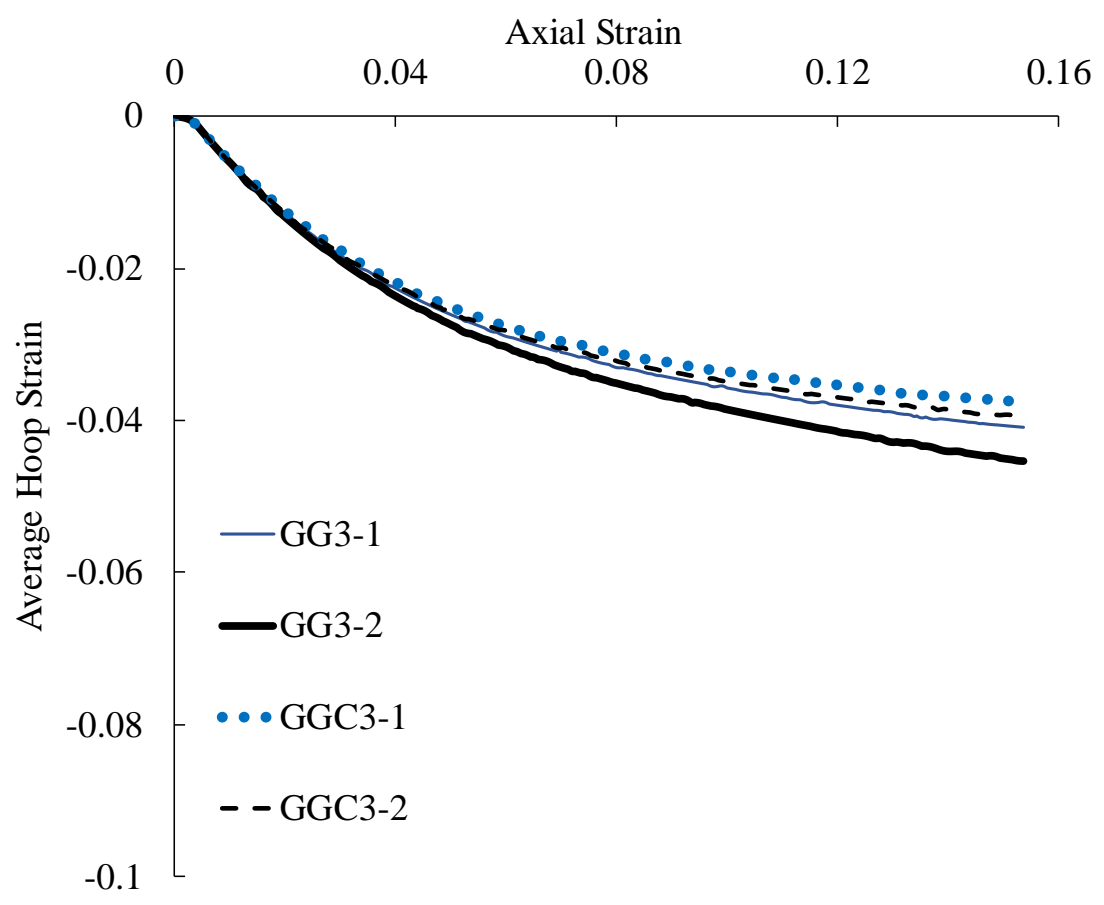

Fig. 21. Comparisons between GG3 and GGC3. 

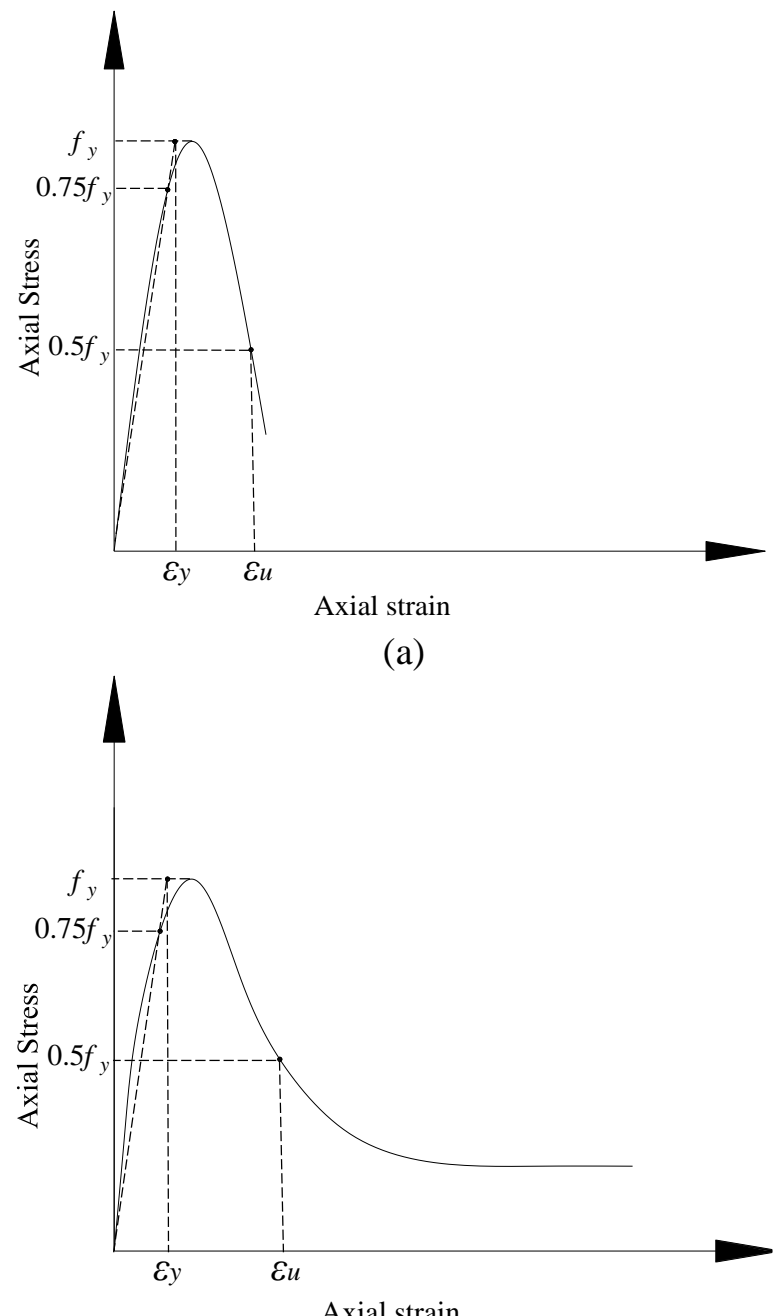

(b)

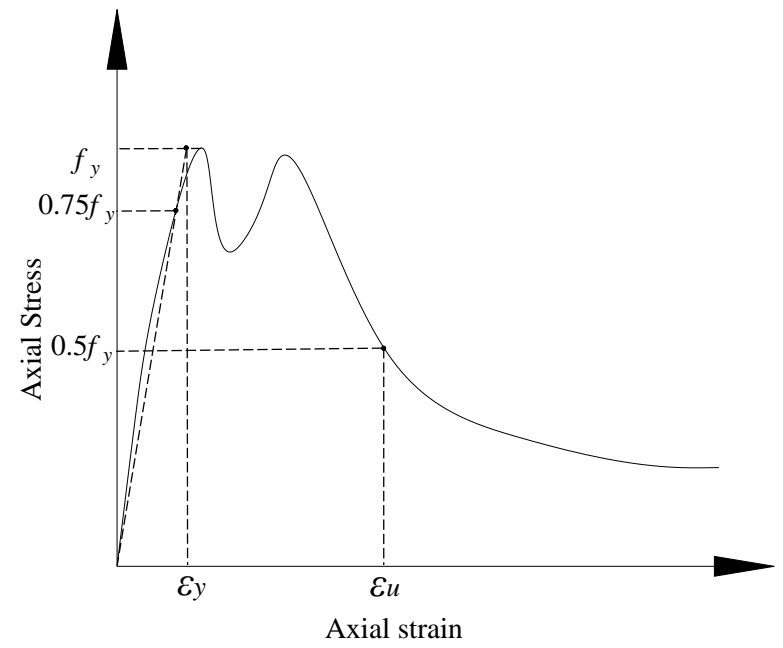

(c)

685 Fig. 22. Definition of $\varepsilon_{u}$ and $\varepsilon_{y}$ : (a) Definition of $\varepsilon_{u}$ and $\varepsilon_{y}$ for unconfined concrete; (b) Definition 686 of $\varepsilon_{u}$ and $\varepsilon_{y}$ for GPGCPs without FPCC; (c) Definition of $\varepsilon_{u}$ and $\varepsilon_{y}$ for GPGCPs with FPCC. 


\section{$687 \quad$ List of Tables}

688 Table 1. Details of the preliminary test samples.

689 Table 2. Details of the GPGCP specimens.

690 Table 3. Mix proportions of PGC and NGC.

691 Table 4. Average material properties of GFRP sheets and PVC dog-bone specimens.

692 Table 5. Results of the preliminary tests.

693 Table 6. Test results of GPGCPs without FPCC.

694 Table 7. Test results of GPGCPs with FPCC.

695 Table 8. Ductility results.

696 


\begin{tabular}{|c|c|c|c|}
\hline Label & Specimen Type & $\begin{array}{l}\text { Outer Diameter } \\
(\mathrm{mm})\end{array}$ & $\begin{array}{l}\text { Inner Diameter } \\
(\mathrm{mm})\end{array}$ \\
\hline P-1 & \multirow[b]{2}{*}{ Plain PGC } & 150 & - \\
\hline P-2 & & 150 & - \\
\hline N-1 & \multirow[b]{2}{*}{ Plain NGC } & 150 & - \\
\hline $\mathrm{N}-2$ & & 150 & - \\
\hline FP-1 & \multirow{2}{*}{ FRP-PVC tubes } & 86 & 76 \\
\hline FP-2 & & 86 & 76 \\
\hline FPCC-1 & & 86 & - \\
\hline FPCC-2 & $\begin{array}{l}\text { FRP-PVC-confined } \\
\text { concrete (FPCC) }\end{array}$ & 86 & - \\
\hline
\end{tabular}




\begin{tabular}{|c|c|c|c|c|}
\hline Label & Specimen Type & $\begin{array}{l}\text { Diameter of the } \\
\text { PGC (or NGC for } \\
\text { plain NGC } \\
\text { samples) }\end{array}$ & $\begin{array}{l}\text { Number of } \\
\text { Geogrid Layers }\end{array}$ & FPCC \\
\hline GG1-1 & \multirow{6}{*}{ GPGCPs without FPCC } & 160 & 1 & - \\
\hline GG1-2 & & 160 & 1 & - \\
\hline GG2-1 & & 160 & 2 & - \\
\hline GG2-2 & & 160 & 2 & - \\
\hline GG3-1 & & 160 & 3 & - \\
\hline GG3-2 & & 160 & 3 & - \\
\hline GGC1-1 & \multirow{6}{*}{ GPGCPs with FPCC } & 160 & 1 & 1 \\
\hline GGC1-2 & & 160 & 1 & 1 \\
\hline GGC2-1 & & 160 & 2 & 1 \\
\hline GGC2-2 & & 160 & 2 & 1 \\
\hline GGC3-1 & & 160 & 3 & 1 \\
\hline GGC3-2 & & 160 & 3 & 1 \\
\hline
\end{tabular}


Table 3. Mix proportions of PGC and NGC.

\begin{tabular}{cccccccc}
\hline Mix & $\begin{array}{c}\text { Coarse } \\
\text { Aggregates } \\
\left(\mathrm{kg} / \mathrm{m}^{3}\right)\end{array}$ & $\begin{array}{c}\text { Sand } \\
\left(\mathrm{kg} / \mathrm{m}^{3}\right)\end{array}$ & $\begin{array}{c}\text { Slag } \\
\left(\mathrm{kg} / \mathrm{m}^{3}\right)\end{array}$ & $\begin{array}{c}\text { Fly Ash } \\
\left(\mathrm{kg} / \mathrm{m}^{3}\right)\end{array}$ & $\begin{array}{c}\text { Sodium } \\
\text { Hydroxide } \\
\text { Solution } \\
\left(\mathrm{kg} / \mathrm{m}^{3}\right)\end{array}$ & $\begin{array}{c}\text { Sodium } \\
\text { Silicate } \\
\text { Solution } \\
\left(\mathrm{kg} / \mathrm{m}^{3}\right)\end{array}$ & $\begin{array}{c}\text { Additional } \\
\left(\mathrm{kg} / \mathrm{m}^{3}\right)\end{array}$ \\
\hline PGC & 1558 & - & 122.0 & 183.0 & 50.8 & 101.7 & 45.8 \\
NGC & 1039 & 675 & 160.0 & 240.0 & 66.7 & 133.3 & 60.0 \\
\hline
\end{tabular}

709

710 
Table 4. Average material properties of GFRP sheets and PVC dog-bone specimens.

\begin{tabular}{cccccc}
\hline Type & $\begin{array}{c}\text { Thickness } \\
(\mathrm{mm} / \mathrm{ply})\end{array}$ & $\begin{array}{c}\text { Tensile } \\
\text { Strength } \\
(\mathrm{MPa})\end{array}$ & $\begin{array}{c}\text { Fracture } \\
\text { Stress (MPa) }\end{array}$ & $\begin{array}{c}\text { Elastic } \\
\text { Modulus } \\
(\mathrm{GPa})\end{array}$ & $\begin{array}{c}\text { Ultimate Tensile } \\
\text { Strain (\%) }\end{array}$ \\
\hline GFRP & 0.15 & 621.5 & - & 33.4 & 1.86 \\
PVC specimen & 4 & 51.2 & 42.7 & 1.58 & 55.4 \\
\hline
\end{tabular}

712

713 
Table 5. Results of the preliminary tests.

\begin{tabular}{lllll}
\hline $\begin{array}{l}\text { Specimen } \\
\text { Label }\end{array}$ & $\begin{array}{l}\text { Maximum } \\
\text { Load }(\mathrm{kN})\end{array}$ & $\begin{array}{l}\text { Maximum } \\
\text { Axial stress } \\
(\mathrm{MPa})\end{array}$ & $\begin{array}{l}\text { Axial Strain at } \\
\text { Maximum } \\
\text { Load }\end{array}$ & $\begin{array}{l}\text { Hoop Strain } \\
\text { at FRP } \\
\text { Rupture }\end{array}$ \\
\hline $\mathrm{P}-1$ & 373 & 21.1 & 0.0021 & - \\
$\mathrm{P}-2$ & 388 & 22.0 & 0.0019 & - \\
$\mathrm{N}-1$ & 871 & 49.3 & 0.0023 & - \\
$\mathrm{N}-2$ & 836 & 47.3 & 0.0021 & - \\
FP-1 & 45.1 & - & 0.0232 & - \\
FP-2 & 44.9 & - & 0.0215 & - \\
FPCC-1 & 457 & 78.2 & 0.0264 & -0.0180 \\
FPCC-2 & 437 & 75.2 & 0.0255 & -0.0183 \\
\hline
\end{tabular}

715

716 

Table 6. Test results of GPGCPs without FPCC.

\begin{tabular}{cccccc}
\hline $\begin{array}{c}\text { Specimen } \\
\text { Label }\end{array}$ & $\begin{array}{c}\text { Peak Axial } \\
\text { Stress (MPa) }\end{array}$ & $\begin{array}{c}\text { Axial Strain at } \\
\text { Peak Stress }\end{array}$ & $\begin{array}{c}\text { Final Axial } \\
\text { Stress } \\
(\mathrm{MPa})\end{array}$ & $\begin{array}{c}\text { Final Lateral } \\
\text { Strain }\end{array}$ & $\begin{array}{c}\text { Final Axial } \\
\text { Strain }\end{array}$ \\
\hline GG1-1 & 21.8 & 0.0021 & 4.8 & -0.083 & 0.113 \\
GG1-2 & 20.9 & 0.0019 & 4.0 & -0.072 & 0.096 \\
GG2-1 & 21.9 & 0.0020 & 5.8 & -0.064 & 0.154 \\
GG2-2 & 22.0 & 0.0021 & 5.7 & -0.059 & 0.154 \\
GG3-1 & 22.1 & 0.0022 & 6.7 & -0.041 & 0.154 \\
GG3-2 & 22.6 & 0.0021 & 7.2 & -0.045 & 0.154 \\
\hline
\end{tabular}

718

719 
Table 7. Test results of GPGCPs with FPCC

\begin{tabular}{|c|c|c|c|c|c|c|c|}
\hline $\begin{array}{l}\text { Specimen } \\
\text { Label }\end{array}$ & $\begin{array}{l}\text { First Peak } \\
\text { Stress } \\
(\mathrm{MPa})\end{array}$ & $\begin{array}{l}\text { Axial } \\
\text { Strain at } \\
\text { First Peak } \\
\text { Stress }\end{array}$ & $\begin{array}{l}\text { Second } \\
\text { Peak } \\
\text { Axial } \\
\text { Stress } \\
(\mathrm{MPa})\end{array}$ & $\begin{array}{l}\text { Axial } \\
\text { Strain at } \\
\text { Second } \\
\text { Peak } \\
\text { Stress }\end{array}$ & $\begin{array}{l}\text { Final } \\
\text { Axial } \\
\text { stress } \\
(\mathrm{MPa})\end{array}$ & $\begin{array}{l}\text { Final } \\
\text { Lateral } \\
\text { Strain }\end{array}$ & $\begin{array}{l}\text { Final } \\
\text { Axial } \\
\text { Strain }\end{array}$ \\
\hline GGC1-1 & 26.2 & 0.0021 & 25.2 & 0.0237 & 7.1 & -0.080 & 0.154 \\
\hline GGC1-2 & 26.5 & 0.0022 & 24.6 & 0.0249 & 6.3 & -0.081 & 0.154 \\
\hline GGC2-1 & 26.6 & 0.0024 & 26.2 & 0.0238 & 8.0 & -0.054 & 0.154 \\
\hline GGC2-2 & 26.2 & 0.0026 & 25.7 & 0.0254 & 8.9 & -0.056 & 0.154 \\
\hline GGC3-1 & 26.4 & 0.0021 & 26.2 & 0.0243 & 9.2 & -0.038 & 0.154 \\
\hline GGC3-2 & 25.9 & 0.0022 & 25.7 & 0.0256 & 10.0 & -0.040 & 0.154 \\
\hline
\end{tabular}

721 
Table 8. Ductility results.

\begin{tabular}{|c|c|c|c|c|}
\hline $\begin{array}{l}\text { Specimen } \\
\text { Label }\end{array}$ & $\begin{array}{l}\text { Yield Strain } \\
\qquad\left(\varepsilon_{y}\right)\end{array}$ & $\varepsilon_{u}$ & Ductility & $\begin{array}{l}\text { Average } \\
\text { Ductility }\end{array}$ \\
\hline P-1 & 0.00193 & 0.0035 & 1.81 & \multirow[b]{2}{*}{1.77} \\
\hline P-2 & 0.00192 & 0.0033 & 1.72 & \\
\hline GG1-1 & 0.00200 & 0.0037 & 1.85 & \multirow{2}{*}{1.80} \\
\hline GG1-2 & 0.00189 & 0.0033 & 1.75 & \\
\hline GG2-1 & 0.00194 & 0.0039 & 2.01 & \multirow{2}{*}{1.97} \\
\hline GG2-2 & 0.00202 & 0.0039 & 1.93 & \\
\hline GG3-1 & 0.00199 & 0.0041 & 2.06 & \multirow{2}{*}{2.14} \\
\hline GG3-2 & 0.00198 & 0.0044 & 2.22 & \\
\hline GGC1-1 & 0.00126 & 0.0479 & 38.0 & \multirow{2}{*}{38.2} \\
\hline GGC1-2 & 0.00128 & 0.0491 & 38.4 & \\
\hline GGC2-1 & 0.00134 & 0.0596 & 44.5 & \multirow{2}{*}{44.9} \\
\hline GGC2-2 & 0.00132 & 0.0597 & 45.2 & \\
\hline GGC3-1 & 0.00136 & 0.0649 & 47.7 & \multirow{2}{*}{53.6} \\
\hline GGC3-2 & 0.00132 & 0.0784 & 59.4 & \\
\hline
\end{tabular}

723

724

725 